\title{
Island country: Aboriginal connections, values and knowledge of the Western Australian Kimberley islands in the context of an island biological survey
}

\author{
T. Vigilante', J. Toohey', A. Gorring1*, V. Blundell', \\ T. Saunders ${ }^{3}$, S. Mangolamara ${ }^{4}$, K. George ${ }^{1}$, J. Oobagooma ${ }^{5}$, \\ M. Waina ${ }^{6}$, K. Morgan ${ }^{6}$ and K. Doohan ${ }^{7}$ \\ ${ }^{1}$ Kimberley Land Council, PO Box 2145, Broome, Western Australia 6725, Australia. \\ ${ }^{2}$ Department of Sociology and Anthropology, Carleton University, 1125 Colonel By Drive, Ottawa, \\ Ontario K1S 5B6, Canada. \\ ${ }^{3}$ PO Box 10, Derby, Western Australia 6728, Australia. \\ ${ }^{4}$ Wunambal Gaambera Aboriginal Corporation, PMB 16, Kalumburu via Wyndham, \\ Western Australia 6740, Australia. \\ ${ }^{5}$ Dambimangari Aboriginal Corporation, PO Box 648, Derby, Western Australia 6728, Australia. \\ ${ }^{6}$ Balanggarra Aboriginal Corporation, c/- Kimberley Land Council, PO Box 821, Kununurra, \\ Western Australia 6743, Australia. \\ 7 PO Box 5404, Albany, Western Australia 6330, Australia. \\ ${ }^{*}$ Corresponding author: ari.gorring@klc.org.au
}

\begin{abstract}
Our paper describes Aboriginal connections, values and knowledge of the Kimberley islands and their resources in the context of a terrestrial biological survey of 24 islands, initiated by the Western Australian Government and coordinated by the Department of Environment and Conservation (DEC). The Kimberley islands represent part of the traditional lands of Aboriginal people in the region and hold great significance and value for them. The Kimberley Land Council (KLC) facilitated the participation of 50 Aboriginal Traditional Owners in this survey, which spanned five Native Title areas, three of which have now been determined (Bardi and Jawi, Wanjina Wunggurr Dambimangari and Wanjina Wunggurr Uunguu) and two of which are still in mediation (Balanggarra and Mayala). The KLC and DEC negotiated a research agreement that provided for managed access to sensitive cultural sites, data sharing, the participation of Traditional Owners in field work alongside scientists and input by Traditional Owners in the final publications and recommendations resulting from this survey.

Our paper also places the island survey and its findings into the broader context of Indigenous Natural and Cultural Resource Management (INCRM) in the Kimberley region, including the development of Indigenous Protected Areas and Indigenous Rangers, and other projects such as fire abatement and tourism management, along with traditional management practices which operate independently from formal management programs.
\end{abstract}

KEYWORDS: Balanggarra, Bardi and Jawi, Dambimangari, Mayala, Traditional Owner, Unnguu, Wanjina Wunggurr 


\section{INTRODUCTION}

The numerous islands and surrounding waters of the north-west Kimberley have been used and occupied by Aboriginal people for thousands of years. This use and occupation has included active and passive management of valuable resources. For the Traditional Owners (TOs) of these islands they are places which represent complex entities of cultural and ecological values; for instance, islands are rarely known by a single name. Instead, they have layered meanings of cultural significance. Complex relationships of caretaking and naming have continued into the present period despite significant geographic and mobility constraints. The islands are covered by several contiguous native title determinations (which recognise private property rights of Aboriginal people in the islands and the seas) and claims. Tenure includes exclusive and non-exclusive possession native title, Aboriginal Reserves and unallocated Crown land.

The islands are components of Indigenous cultural landscapes and seascapes that are of enormous significance to TOs. As such, islands are elements of the complex enculturated space which Kimberley TOs call their 'saltwater country'. As such, they include many specific sites that are focal points in the naming of islands, in local and regional religious narratives, for ceremonial practices and other cultural activities. The islands also have important freshwater, plant and animal resources. In recent times, TOs have undertaken natural and cultural resource management projects and programs aimed at identifying and managing the values and resources in their traditional country, including islands. The natural and Indigenous cultural values of the islands have also been recognised in the recent listing of the West Kimberley on the National Heritage List under the Environment Protection and Biodiversity Conservation Act 1999 (Cth) (EPBC Act) (Australian Heritage Commission [AHC] 2011).

The Kimberley Islands Biodiversity Survey (KIBS) was developed by the Western Australian Department of Environment and Conservation (DEC). The impetus for the survey was the need to obtain baseline information on the biodiversity values of the islands for future management planning (Gibson and McKenzie 2012). The Kimberley islands are of high conservation value, containing many endemic and threatened species which are, to some extent, protected from threatening processes prevalent on the mainland.

The KIBS project demonstrated best practice for involving TOs in a research partnership. The KLC and DEC negotiated a research agreement that provided for managed access to sensitive cultural sites, data sharing, the participation of TOs in field work alongside scientists, and input by TOs into the final publications and recommendations resulting from this survey. The KLC is the Native Title Representative Body for the Kimberley and also supports native title groups in natural and cultural resource management through its Land and Sea Management Unit.

Gibson and McKenzie (2012) provide a detailed outline of the context, objectives and approach of the KIBS. This paper aims to provide an overview of TO connections, knowledge, values and management plans for Kimberley islands to complement other publications arising from the KIBS project. It is organised into four major sections. The first section describes the methods and approach employed in this project. The second section discusses the territories as well as the cultural and linguistic characteristics of the Aboriginal people connected to islands in the surveyed area. Colonial impacts on their cultures and relevant aspects of native title and land tenure are also discussed. Section three addresses issues regarding Indigenous natural and cultural resource management, including the nature of Aboriginal occupation and knowledge of islands as well as Indigenous values associated with islands. The final section considers issues regarding the future management of islands.

\section{METHODS AND APPROACH}

\section{RESEARCH AGREEMENT AND TRADITIONAL OWNER ROLES AND PARTICIPATION IN THE SURVEY}

For research projects to be truly collaborative TO groups need to be involved at the project development stage so that they share the research agenda and concept. In the case of the KIBS, the State had already developed a project proposal in order to secure funding from Commonwealth and State Governments. In this case, the KLC (acting under TO instruction) agreed to negotiate a research agreement with DEC prior to the research commencing. In the past, there has been little or no impetus for State Government agencies to engage with Kimberley TOs in biological survey work although there are records indicating that TOs have attempted to secure a role in these processes (Johnston and Tann 1991). Earlier biological surveys in the region, including an earlier survey of islands of the Bonaparte Archipelago (Burbidge and McKenzie 1978), did not involve TOs, with one notable exception. This was the Kimberley Rainforest Survey (McKenzie et al. 1991) which provides a precedent for $\mathrm{TO}$ participation in biological survey work. Here, the project leaders invited a senior Wunambal elder, Geoffrey Mangglamara $^{\dagger}$, to join the field team and co-write 
a paper on indigenous knowledge of rainforests (Mangglamarra et al. 1991). There are also other precedents from elsewhere in the state (Pearson and the Ngaanyatjarra Council 1997; Brennan 2012).

The research agreement for the KIBS set a new standard for collaborative research with TOs in the North Kimberley. It included a number of important provisions, such as the following:

- Field teams were accompanied by TOs to ensure cultural heritage could be protected.

- In accordance with Aboriginal law and culture, visitors needed to be welcomed to country by TOs, and often this required some form of ceremony such as a smoking ceremony.

- TO participation in the field teams ensured that TOs could impart relevant local and traditional ecological knowledge to the team and also that TOs gained valuable new skills and knowledge from the non-indigenous scientific team members (including some of the State's leading biologists).

- The research agreement also required that data would be provided to the KLC at the end of the project. It also made provisions for the KLC to review and contribute to final publications to ensure that the interests of TOs are considered.

Since the signing of this agreement, the KLC has established a research and ethics committee and developed a policy to guide future research projects that relate to TOs and their land and sea interests (http://klc.org.au/2010/12/02/klcresearch-protocol/).

\section{TRADITIONAL OWNERS AND FIELD WORK}

The general KIBS methods have been outlined by Gibson and McKenzie (2012). The survey involved sampling of 24 islands over three years with both dry season and wet season surveys. Sampling targeted mammals, reptiles, frogs, land snails, birds and vascular plants. Prior to the field work, DEC staff provided KLC with maps and satellite images of proposed field sites. Based on these maps and images, senior TOs advised if there were any cultural heritage issues that would make these sites unsuitable for access. In some instances TOs also joined DEC staff in a fly-over of some of the proposed sites. This desktop approach to cultural heritage site identification is not ideal as some Indigenous people are not familiar with using maps, and small islands within archipelagos can be difficult to recognise from maps. However, funds did not allow for on-ground site visits prior to the survey.

Each field team included one or two TOs. These TOs were selected by the relevant native title group and were people with connections to the specific islands or broader country within which the island was located. Over the three years of the project 50 TOs took part in field work. Their names are compiled in Appendix A (see also Appendix A in Gibson and McKenzie 2012). Traditional Owners played a number of roles on the field team. On arrival at the site, they were asked to provide an initial heritage site clearance to make sure that any sensitive cultural sites in the area had not been missed in the desktop approach. It was also important to ensure that activities did not disturb cultural heritage sites. Some significant stone arrangements were recorded at a number of sites and were documented for future reference. Traditional Owners were also required to participate in the field work with the scientific team. The level of experience and knowledge varied widely among TO participants. Some older people had grown up 'on country' and were knowledgeable about various animals and plants, while others who were young and had grown up 'in town' were less knowledgeable. For many younger participants this was their first time on the surveyed island and it was therefore a valuable experience for them.

Following the field program, some TO participants were interviewed using semi-structured interviews to document their experiences of the survey and, where possible, photographs and cultural site data were also compiled from field teams.

\section{DATA SOURCES}

This paper draws on information contained in both published and unpublished sources. Published sources are cited throughout the text. Other information derives from semi-structured interviews that were recorded by the authors of this paper with Aboriginal elders from various Aboriginal language groups associated with the KIBS (including members of the Angus and Stumpagee families, Daphne Wilfred, Janet Oobagooma, Victor Barunga ${ }^{\dagger}$, Jack Karadada ${ }^{\dagger}$, Basil Djanghara, Sylvester Mangolomara, Sylvia Djanghara, Matthew Waina, Mary Taylor, Lionel Mitchell, George Dixon and Selwin Meehan), and with Aboriginal field participants in the KIBS (as named in Appendix A). Statements attributed to Aboriginal people are indicated and credited throughout the text. This paper also draws on data from earlier unpublished research and from personal communications with TOs. Notes from field trips undertaken by the Kimberley Land Council with Mayala TOs as part of the North Kimberley Saltwater Country Project also provided some source material. 


\section{INDIGENOUS CONTEXT FOR THE KIMBERLEY ISLAND SURVEY}

\section{PROJECT AREA - SOCIAL SETTING, NATIVE TITLE, LAND TENURE AND ABORIGINAL CONNECTION}

The islands sampled during the KIBS are located across the Traditional Countries of several Aboriginal territorial groups. Historically, these groups have been referred to by anthropologists as 'tribes' (Tindale 1940, 1974) and more precisely as 'language groups' (Blundell and Woolagoodja 2005; Kimberley Land Council [KLC] 2010; AHC 2011). For Kimberley Aboriginal people, language is a part of their country, and a group's name and the language of its overall territory are usually the same or similar (McGregor 2004). In some cases, several Kimberley language groups comprise larger Aboriginal societies, referred to as 'native title communities' in native title materials (see below). Society members generally intermarry and they share beliefs and practices that set them apart from other Kimberley Aboriginal societies. Within the overall country of a particular language group, individuals are members of descent groups sometimes called 'clans,' and as such they are connected to smaller areas of land called 'clan estates' by anthropologists, or 'my country' by TOs themselves. Each language group has its own term for these estates, such as dambeema (Worrorra), guraa (Wunambal and Gaambera), kûraa (Pelaa), and booroo (Bardi). Typically, each person has a primary connection to the estate of their father, with associated rights and duties. Individuals also have strong connections, with associated rights and duties, to the estates of their other close kin.

In recent years, Aboriginal people have formally defined themselves in terms of native title groups for the purpose of securing recognition of legal title through the Native Title Act 1993 (Cth). Native title groups are often composed of one or more language group whose members comprise a distinct Aboriginal society as well as a single native title community (Table 1, Figure 1).

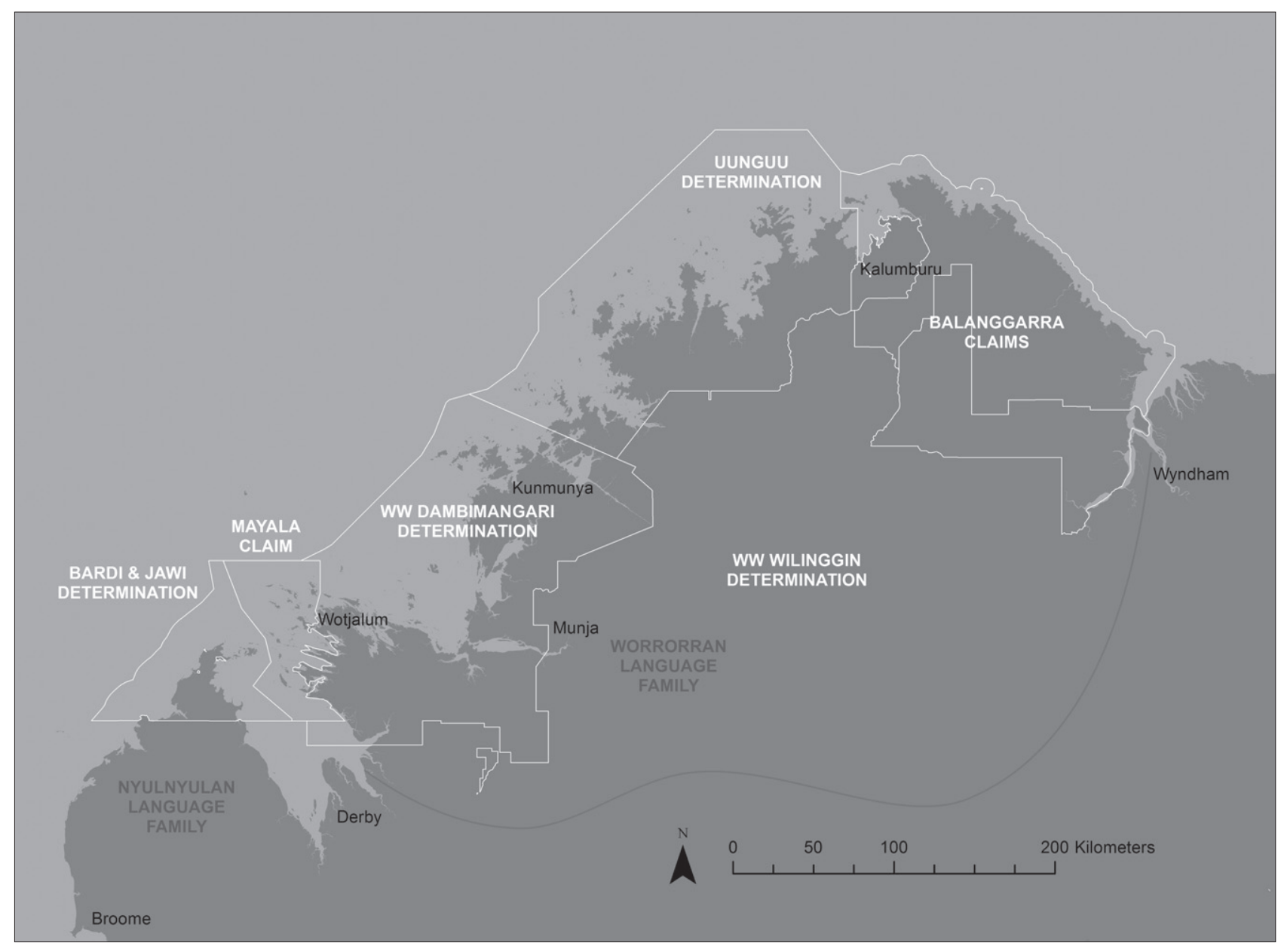

FIGURE 1 Map of coastal language families, languages, language groups and native title groups covering the Kimberley Island Biodiversity Survey area. 
ڤ)

० ऽ ऽ

응ํํ

要要

๘ 흄

흐을

응 $\frac{0}{0}$

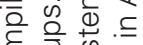

잉 음 몯

(1) 응

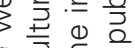

凹 उ है Ф

(1)

ㄷำ

$\frac{0}{2} \frac{\omega}{\pi}$ त

ठठ 을 음

$\sum$ 远

幽.

듣

음 은 क्ष

攺选

()

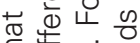

ᄃ专的完

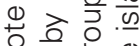

\% के

む)

文迹蒙范

ज 世

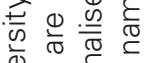

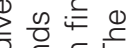

$\frac{\mathbb{C}}{\mathbb{N}}$

$\underline{0} \underline{\varepsilon}$

다에

ज)

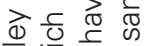

这

है حิ

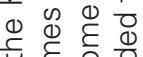

$\subseteq \stackrel{\frac{1}{\tau}}{\complement}$ \&

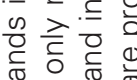

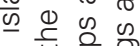

후ㅇㅝㅡㄹ

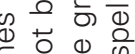

동

ब

즘흐 웅

ठํ ब

항

흘

폼

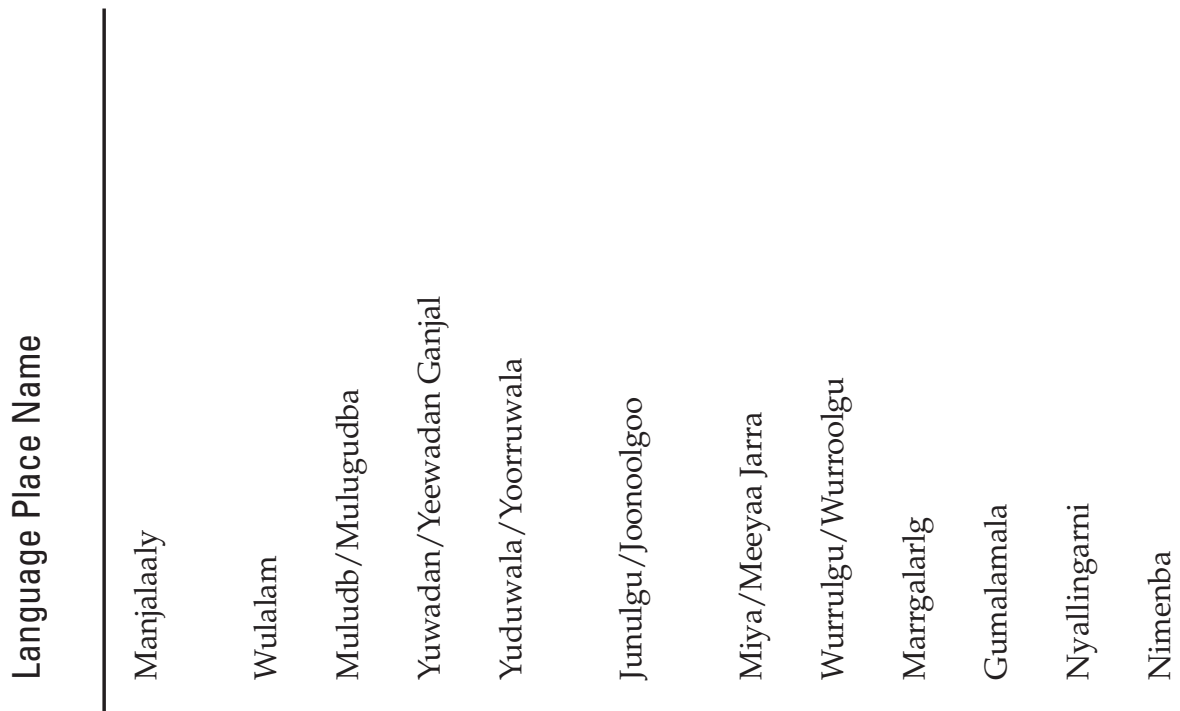

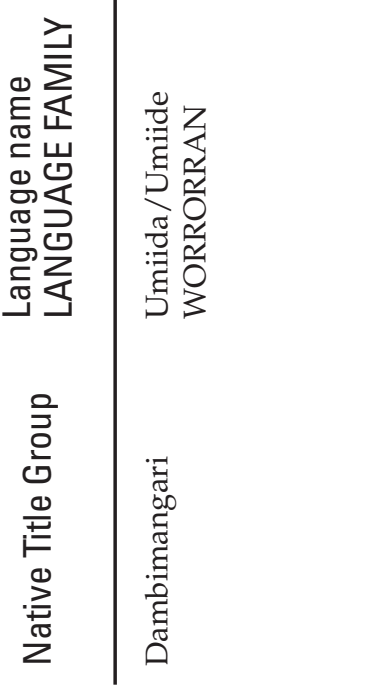

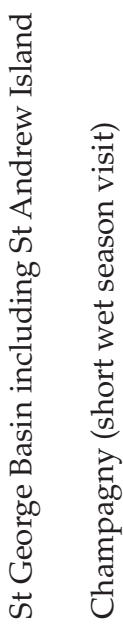

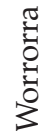

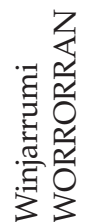




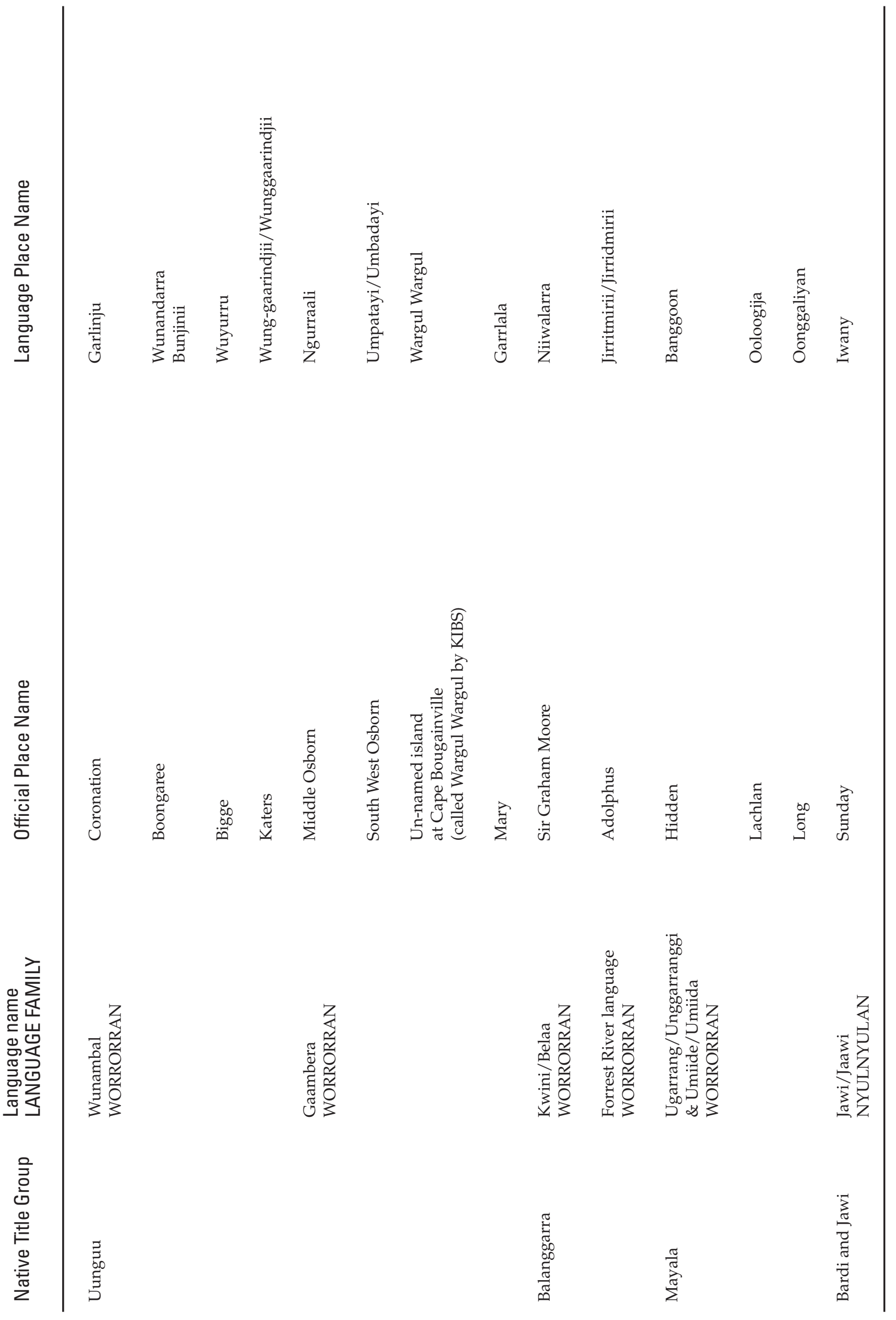


The Wanjina Wunggurr native title community covers most of the North Kimberley with their overall territory consisting of the Wilinggin, Uunguu and Dambimangari native title determination areas. Members of the Wanjina Wunggurr community share a law and culture derived from Wanjina and Wunggurr ancestral beings (described below). Within the overall Wanjina Wunggurr community, the Wunambal and Gaambera language groups and the Wunambal and Gaamberra languages are associated with the Uunguu determination area, while the Worrorra language group and the Worrorra language are associated with the Dambimangari determination area. There are also Wanjina Wunggurr people who are the TOs of islands and adjoining waters in the Dambimangari native title area associated with the Yawijibaya, Winjarrumi, Umiida and Unggarrangi languages, which are no longer spoken but were closely related to Worrorra. Members of the Dambimangari and Uunguu native title groups have strong connections to islands which form part of their traditional country. The Wanjina Wunggurr native title community also predominately includes the Ngarinyin language group associated with the Ngarinyin (also known as Ungarinyin) language, and whose Wilinggin native title claim area lies inland from the coast.

The Balanggarra Native Title claim area stretches from Napier Broome Bay to Cambridge Gulf and Wyndham town. TOs associated with the Belaa (also known as Kwini) and Yeiji language groups and the Argna, Arawari, Gular and Guragona 'tribes' among others are connected to this country with a distinctive set of local laws and customs (Kaberry 1934, 1935a, 1935b; Ben Ward \& Ors v. Western Australia \& Ors [1998] FCA 1478 [24 November 1998]). The Bardi and Jawi native title community includes the Bardi language group from the tip of the Dampier Peninsula and the Jawi from Sunday Island and other neighbouring islands. The Mayala native title claim covers many of the islands of the Buccaneer Archipelago and Sunday Strait.

The 24 islands in the KIBS cover the country of some 10 language groups. The majority of the languages in the North Kimberley area belong to a distinct Australian language family, the Worrorran. All of these languages are derived from an ancestral language called a proto-language, a single language source (see McGregor and Rumsey 2009). One of the typological characteristics of this family is that its languages have several (four or more) gender terms or noun classes. Jawi belongs to the Nyulnyulan language family together with Bardi and other languages found predominantly on the adjacent Dampier Peninsula and adjacent lower Fitzroy River catchment. These languages have no gender or noun classes.

Bardi and Jawi are very similar languages with some slight differences in vocabulary; for example, the noun for 'dugong' is odorr in Bardi and urdorr in Jawi (Bowern 2007). There are also grammatical differences; for example the inflected form 'for fighting' is biilingan in Bardi and biilan in Jawi note the different purposive case ending (Bowern 2008). Yawijibaya and Umiida are closely related to Worrorra. There are some differences in verb forms for example compare Yawijibaya beyagal, Umiida bayalgolgo with Worrorra bengkaal, all meaning 'come here'. Grammatically, the ablative case (meaning 'from') also differs, Yawijibaya $-g a$, Umiida -naga and Worrorra -aalb(a) (McGregor and Rumsey 2009). Areas associated with Jawi, Yawijibaya and Winjarrumi languages consist entirely, or largely, of islands and ocean water, while areas associated with the other language groups in the survey areas include islands and ocean waters as well as large sections of the mainland, such as for Wunambal.

\section{ARCHAEOLOGICAL EVIDENCE OF OCCUPATION AND COLONIAL IMPACTS}

Archaeological evidence suggests that Aboriginal people have occupied north-west Australia for at least 40,000 years and that the Kimberley was a likely entry point for the arrival of the first people across land bridges from Asia (Mulvaney and Kamminga 1999). Throughout this period, sea levels have risen and fallen with glaciations, and offshore islands have rejoined the mainland and separated again. O'Connor (1989) has remarked that there are relatively few archaeological remains on many islands despite ethnographic evidence of long and intensive occupation. However, some significant archaeological deposits have been investigated in rock shelters on High Cliffy Island, Koolan Island and Macleay Island, confirming a long history of island occupation as early as 27,300 +/- $1100 \mathrm{BP}$ based on radiocarbon dating of deposited materials. Other islands have rock art, stone arrangements, shell middens and scattered artefacts.

Estimates suggest that prior to European colonisation, the total Aboriginal population in the coastal area between Yampi Sound and Cape Londonderry was in the vicinity of 4000 people (Crawford 1969).

In many cases, Aboriginal people residing on islands experienced greater or earlier impacts from colonisation than those on the mainland (Crawford 2001). Much of the early colonization came from the sea, followed later by land-based expeditions and pastoralism (Jebb 2002). Also, because of their smaller countries and smaller numbers of people, the island people and languages may have been 
more susceptible to the effects of colonisation. Of the three distinct island languages in the Kimberley (Yawijibaya, Winjarrumi and Jawi), only Jawi is still spoken - albeit by a small number of old people. By comparison, larger culturally distinct language groups remain on large islands in the Northern Territory, namely the Tiwi on Melville and Bathurst Islands and the Anindilyakwa on Groote Eylandt; these languages still being spoken by more than a thousand people. The 2005 National Indigenous Languages Survey Report estimated approximately 1500 speakers of Anindilyakwa, whereas the 2006 Australian Bureau of Statistics Census counted 1283 speakers (www.sorosoro.org/en/anindilyakwa), accessed June 2012).

Makassan sea traders (from present day Indonesia) had already begun visiting the Kimberley coast from sometime between 1669 and 1763 (Crawford 1969; 2001). They established seasonal camps and processing centres for sea cucumber, including on some islands - Jar, Woku-Woku, Low, Corronade, Champagney, Augustus and Cassini (Crawford 2001), and operated between Cape Londonderry in the north and Brue Reef in the south. Aboriginal people's interactions with Makassans varied. There was some exchange of language, trade and marriage partners (Crawford 2001). Some groups worked with Makassans in the harvest of sea cucumber. The Juarinanda people of Sir Graham Moore Island adopted many words of possible Malay origin into their language and personal names of individuals were derived from Malay boating terms (e.g. Lain-moro, the gap between two ships lying parallel at anchor) (Hernandez 1941; Crawford 2001). Aboriginal people in the Kimberley also obtained dugout canoes from Makassans and local indigenous words for canoe 'namandi' and 'barawa' may have been derived from Malay dialect (Crawford 2001), but this remains to be tested. However, evidence also suggests that relations between Aboriginal people and Makassans in the Kimberley region were often hostile and that Aboriginal people changed their movement patterns between islands and the coast, and the inland to avoid Makassans (Crawford 1983).

European seafarers began to arrive soon after the Makassans and found that Aboriginal people had already adopted hostile behaviours to visitors, sending smoke signals to warn each other of the arrivals and, in some cases, lighting fires to drive the visitors away (Sholl 1865 cited in Crawford 2001; Perez 1977; Crawford 1969; 2001). The first European visitors were mostly navigators and explorers, including William Dampier in 1688 and 1699 (Dampier 1981 [1699]), Baudin in 1801 and 1803 (Baudin 1974 [1803]); King from 1819 to 1822 (King 1969 [1827]) and Stokes in 1838 (Stokes 1846). In one of the earliest recorded encounters on 17 September 1819, Phillip Parker King documented Aboriginal people on Lacrosse Island harvesting turtle eggs and burning vegetation (King 1969).

Explorers were soon followed by colonists. Most significant, was the failed attempt to establish a pastoral colony at Camden Sound, which brought Europeans into conflict with coastal Worrorra people in the 1800s (Martin 1864; Richards 1990; Crawford 2001). There are Aboriginal oral accounts of conflict and massacres taking place between early seafarers, including some on islands such as Mary Island and Sheep Island (Crawford 2001).

The emerging pearling industry in Western Australia expanded north and led to the establishment of the township of Broome in the 1880s (McGonigal 1998; Edwards 1991). During this time coastal Aboriginal people were forced into indentured or slave labour (AHC 2011). From the 1890s pearling luggers from Broome also began to exploit the North Kimberley, often coming into conflict with Aboriginal people (Crawford 2001). By the 1920s the conflict had eased somewhat. Pearlers and beachcombers encouraged Aboriginal people to remain on the coast to work on luggers or in camps during the dry season rather than move inland, causing some disruption to traditional lifestyle (Crawford 2001). During this time, both Herbert Basedow (1918) and E.J. Stuart (1923) undertook coastal voyages on luggers and recorded their observations of the coast. Their accounts suggest that there were still reasonable numbers of Aboriginal people residing on islands at this time, despite the increasing colonial presence. They encountered Aboriginal people or evidence of Aboriginal people on many islands still living traditional lifestyles. Basedow (1918) also documented the detailed island knowledge of Aboriginal men from Sunday Island who worked as crew on his vessel. In 1916, in the far north of the Kimberley, he observed that 'natives are often seen on rafts' in the area of the Holothuria Banks, between Penguin Shoal and Warn Rock (Basedow 1918).

Following the failed pastoral attempts at Camden Sound, more pastoralists and farmers began to settle in the North Kimberley, near Wyndham and Derby but also further north, including on Sir Graham Moore Island and Barton Plains (Crawford 2001). The Victorian Pastoral Company built a homestead near Forrest River in 1886 (Green 2008). Conflict between pastoralists and Aboriginal people led to killings and massacres and police patrols began capturing Aboriginal people and imprisoning them in gaols in towns (Jebb 2002). The most recent and well documented massacre occurred near Forrest River in 1926 where a police patrol killed a large, but unknown, number of people (Green 2008). 
Contact with Europeans brought new disease epidemics, such as leprosy and influenza, which exacted a huge toll on Aboriginal people. An epidemic was said to have swept through the North Kimberley coast in 1880 with so many people killed that mortuary ceremonies could not be performed (Green 2008). Crawford (2001) provides an account of the Juarinanda people of Sir Graham Moore Island who are said to have been killed in the late 19th century by a mysterious disease involving worms under the skin, with the remainder of the local population moving to Drysdale River Mission. Drysdale River Mission diaries also document epidemics, coupled with low birth rates and intertribal killings (Perez 1977).

Christian missions were established along the coast in the 1890s and early 1900s at Lombadina, Sunday Island, Port George/Kunmunya/Wotjalum, Drysdale River/Kalumburu and Forrest River. The Christian missionaries wanted to protect Aboriginal people from colonial impacts and convert them to their denomination (Choo 2001). Over time, Aboriginal people became increasingly settled at missions but it was common practice for groups of people to return to the bush for some periods to observe cultural traditions and a traditional lifestyle (Crawford 2001; Blundell and Woolagoodja 2005). With the threat of Japanese invasion during WWII, police patrols forced all but a few people remaining in the bush to move to settlements (Choo 2001). Missions often supported themselves with shelling work that also enabled Aboriginal people to visit island country. As was the case for Janet Oobagooma who, until she was about 11 years old, grew up on the islands in the coastal region out from Kunmunya with her grandparents and other old people. They stayed on the islands throughout the year - even during cyclones - using canoes to travel and hunt for foods. Before Kunmunya Mission moved to Wotjalum around 1953, Worrorra people used to travel to Augustus Island for Christmas and Easter holidays and for 'shelling work', collecting pearl shell, baler shells, cowrie shells and living off bush tucker like yams and fruits. Similarly, Sunday Island Mission was sustained by shelling work until it closed in the 1960s. Aboriginal people from Sunday Island Mission spent several weeks camped on various islands during the holiday times collecting trochus shell throughout the Buccaneer Archipelago; Daphne Wilfred spoke of doing this in her childhood. After the 1950s, Wotjalum and Sunday Island were forced to close or relocate closer to towns due to lack of finances. Forrest River Mission also closed in 1968 but was re-established as Oombulgurri four years later. This led to a period of dislocation before communities re-established themselves at Old Mowanjum,
One Arm Point and Oombulgurri. A number of outstations were established during the 1970s and 1980s with the support of government funded programs, including Nilagoon on Sunday Island (however, it is no longer permanently occupied).

Today, TOs predominantly reside in the communities of One Arm Point, Djarinjin/ Lombadina, Mowanjum, Kalumburu, Oombulgurri and the towns of Broome, Derby, Wyndham and Kununurra. Small outstations exist at Cone Bay (Yaloon), Kandiwal (Mitchell Plateau), adjacent to Kalumburu, and adjacent to Oombulgurri. It is difficult to provide current and accurate population figures for TO groups with connections to the area of the KIBS. However, there are at least several thousand TOs with connection to the saltwater country covering the islands in this survey.

\section{NATIVE TITLE RIGHTS AND INTERESTS}

'Native title' is a form of interest in land and waters recognised by the common law of Australia. Unlike other forms of land tenure, it is derived from legal systems outside the current Australian legal system, but if it meets certain criteria it can be recognised by Australian laws. The 'other' legal systems from which native title comes are the laws and customs of the Aboriginal society, community or group who were in occupation of the claimed area of land or waters at the time that the British asserted sovereignty (in Western Australia, 1829). If native title claimants can demonstrate that the claimed land and waters were traditionally owned by their ancestors under a system of laws and customs which has continued to be observed through to the present, and certain other legal criteria are met, the common law of Australia will recognise the 'native title rights and interests' in the claimed area.

Like other land interests, native title rights can be either exclusive (like freehold title) or nonexclusive (like pastoral or other limited purpose leases). Native title interests in land and waters are private property interests which are protected by the common law from wrongs such as trespass or nuisance, in the same way that other land interests are protected. However, because claims for recognition of native title can take in excess of a decade to resolve, claims which are not yet determined (or recognised) by the Federal Court provide some protection if they meet certain technical criteria and are registered on the Register of Native Title Claims. These pre-determination protections are limited to procedural rights in relation to proposals to grant competing interests over the claimed area, such as a proposal to grant a lease or a mining or exploration tenement. 


\section{LAND TENURE AND NATIVE TITLE}

During the early 1900s the Government of Western Australia declared Aboriginal Reserves over some lands adjacent to Aboriginal missions and settlements, including Sunday Island, Wotjalum, Munja, Kunmunya, Admiralty Gulf, Cape Bougainville, Kalumburu and Forrest River. In 1949, the Australian Presbyterian Board of Missions applied, with partial success, for the Kunmunya Reserve to be extended to include islands off the coastline (Augustus Island and parts of the adjacent Bonaparte Archipelago, and the High Cliffy and Montgomery islands, and parts of the adjacent Buccaneer Archipelago) and waters adjacent to protect Aboriginal interests in native dugong, turtle and fishing grounds from the intrusion and exploitation by non-Aboriginal people (Department of Land Administration File 55426 based on Government Gazettes, 13-06-49). The islands were annexed but the waters were not included in the reserve. Many other islands remain unallocated Crown Land (meaning land over which no other tenure has been created), including Bigge, Adolphus and Long islands. Part of Sir Graham Moore was leased in the 1920s to grow cotton but this lease has long since expired.

Over the last 20 years, the State Government has released planning documents recommending conservation reserves for several islands (Burbidge et al. 1991; Burbidge and McKenzie 1978) as well as marine reserves (CALM 1994). In 2010 the State Government released the Kimberley Science and Conservation Strategy which includes a proposal to declare reserves over some 30 islands (http://www. dec.wa.gov.au/content/view/6171/2183/. Accessed 10/06/2012). These reserve proposals are subject to negotiation with native title holders.

The majority of the area of the KIBS was covered by native title claims in the period that the surveys were done, and the balance of the area was subject to a native title determination. In the period since completion of the KIBS, the majority of the area subject to native title claims has been recognised in two further determinations to be subject to both exclusive and non-exclusive native title rights and interests.

These claims and determinations cover the islands, seas, reefs, intertidal zones and adjacent mainland. At the commencement of the KIBS there was only one native title determination, the Bardi Jawi native title determination. The Wanjina Wunggurr Dambimangari native title claim and the Wanjina Wunggurr Uunguu native title claim were subsequently determined on 26 and 23 May 2011, respectively. The registered native title claims are the Mayala native title claim and the Balanggarra Combined native title claim.
As noted above, native title rights and interests can be recognised as 'exclusive' or 'non-exclusive'. While the actual content of these rights and interests will depend on the rights that come from traditional laws and customs, exclusive possession native title rights and interests are the rights to possess, occupy, use and enjoy land and waters as against the whole world. Non-exclusive native title rights and interests will depend on customary rights in the land, but often include the following rights and interests:

- To live on the land, camp, erect shelters and move about the land and waters;

- To engage in cultural activities on the land and waters, including the protection of places of cultural significance from physical harm; and

- To hunt and fish the land and waters and use the resources of the land.

\section{INDIGENOUS NATURAL AND CULTURAL RESOURCE MANAGEMENT}

Aboriginal peak bodies dealing with land, law, culture and language have emerged over the last 30 years including the KLC and its Land and Sea Management Unit, the Kimberley Aboriginal Law and Culture Centre (KALACC) and the Kimberley Language Resource Centre. The last 20 years has also seen the emergence of a formalised Indigenous natural and cultural resource management movement.

The movement of people from their lands and seas during the colonization period created a context where traditional practices were constrained and which saw the rise of some environmental problems. Most significantly, given the events of colonisation, the difficulty of maintaining traditional land management through seasonal burning by Aboriginal people across some remote areas has led to a rise in large and intense unmanaged wildfires in the late dry season (Vigilante et al. 2004). Bowman et al. (2001) coined the phrase 'the Wilderness Effect' to explain the environmental consequences of people moving 'off country'. There has also been a rise in physical and social/cultural impacts on cultural values and at sites of significance, largely because of unmanaged visitation from tourists, government land managers, pastoralists and mining and exploration companies (discussed below).

One area of particular concern to TOs is the largely unregulated expedition cruise industry accessing Aboriginal cultural sites and Aboriginal lands without consent (Scherrer et al. 2008, 2011; Smith et al. 2009; Scherrer and Doohan 2011). In response to these concerns, the KLC initiated The Saltwater Country Project with North Kimberley 
coastal TOs in 2004. The Saltwater Country Project aims to document TO values and concerns for the coastal region and develop management strategies to protect cultural values. The project resulted in the development of a plan with recommendations from TO groups about the ways to manage tourist visitation through permits, Aboriginal ranger programs and Indigenous Protected Areas (IPAs) (North Kimberley Saltwater Country Plan 2010). An IPA is a voluntary conservation covenant registered on the Australia National Reserve System to International Union for Conservation of Nature (IUCN) classification with an objective to protect at least $75 \%$ of the area. There is also a funding commitment from the Australian Government. A number of TO groups (including Wanjina Wunggurr Uunguu and Bardi and Jawi) have now established Aboriginal Rangers through the Australian Government's 'Working On Country Program'. Five coastal groups are also developing IPAs with funding from the Australian Governments IPA Program. IPA management plans are being developed using a participatory planning tool developed by The Nature Conservancy called Conservation Action Planning (The Nature Conservancy 2011; Moorcroft et al. 2012). In 2010 Wanjina Wunggurr Uunguu TOs became the first Kimberley coastal native title group to declare an IPA over two large Aboriginal reserves. It also released its 'Healthy Country Plan' with support from Bush Heritage Australia and the KLC (Wunambal Gaambera Aboriginal Corporation [WGAC] 2010). Other significant natural and cultural resource management projects are the Bardi-Jawi Dugong and Marine Turtle Management Project (Kennett and Kitchens 2009), the North Kimberley Fire Abatement Project (http://klc. org.au/land-sea/north-kimberley-fire-abatementproject/; Fitzsimons et al. 2012) and Traditional Knowledge recording projects (Horstman and Wightman 2001; Karadada et al. 2011).

In 2008, the Australian Heritage Council commenced a National Heritage assessment of the West Kimberley. The assessment involved identifying natural, historic and Indigenous values that meet the technical criteria. The KLC was funded by the Commonwealth to work with TOs to identify values of outstanding heritage value to the nation. TOs wanted the entire West Kimberley to be listed for its heritage values. Although they have their own distinct cultural traditions, they share a common history of resistance, survival and adaption over many thousands of years, with the result that their 'stories', cultures and history are interconnected. On 31 August 2011, following a comprehensive culturally appropriate consultation process, the West Kimberley as 'one place with many stories' was included on the National Heritage List by the Commonwealth Minister for the Environment (see AHC 2011). The listing of the West Kimberley on Australia's National Heritage list led the federal Environment Minister Tony Burke to remark that this is the nation's largest land-based National Heritage listing and the first to proceed with the full consent of the TOs (http:// www.ens-newswire.com/ens/aug2011/2011-08-3101.html. Accessed 30/03/2012).

The following themes and their associated heritage values were authorised by TOs and were ultimately included in the listing (see AHC 2011; http://www.environment.gov.au/heritage/places/ national/west-kimberley/index.html. Accessed 17/04/12):

- Wanjina Wunggurr cultural landscape and sea-scape, including rock art and other manifestations of Wanjina Spirit Beings, and Gwion Gwion/Girrigorro rock art (Gwion Gwion and Girrigorro are descriptive terms used by North Kimberley language groups to refer to a particular type of rock art and associated narratives found in the region. We also note that Balanggarra often spell Girrigorro as Kirakiro or Kirrakirro).

- The Fitzroy River Catchment cultural landscape, described through the narratives of the Snake (Rainbow Serpent).

- The double log raft (Kalwa/Kalum often spelt as gaalwa by Bardi and galam by Worrorra).

- Pearl stories - riches of the sea. The description of this value also includes the concept of wunan /wurnan cultural trade and exchange.

- Bungarun Leprosarium, sites associated with the Noonkanbah dispute, the Bunuba resistance and the role of Jandamarra and Sacred Heart Church at Beagle Bay, all of which TOs authorised for listing as part of the listing's overall theme of resistance, survival and adaptation.

\section{INDIGENOUS KNOWLEDGE OF ISLANDS AND THEIR BIODIVERSITY}

The physical environment and setting of the 24 islands and the wider region has been described by Gibson and McKenzie (2012). TOs have their own detailed system of classifying landscape and seascape features. For example, TOs use the concept 'saltwater country' (lalanggarram in Worrorra [Clendon 2000] and gaarra in Bardi [Aklif 1999]) in an effort to demonstrate to others that their country - no matter what its component parts (water, reef, salt water, islands, beaches and the hard ground of the mainland or of rivers) - is meaningful (see for instance WGAC 2010). At the more local and tangible level, Indigenous classification of country 
emphasizes soil type and geomorphology which influence the distribution and abundance of plant and animal resources. These same classifications apply to islands as microcosms of the mainland (Crawford 1982). Each TO language group has its own word for islands, including Iinalang (Bardi - Aklif 1999), Ungajon (Worrorra - Janet Oobagooma pers. comm.), Uumerige (Wunambal - Jack Karadada ${ }^{\dagger}$, pers. comm.) and Mudu (Belaa Crawford 1982).

The plant and animal knowledge of North Kimberley TOs has been documented by ethnographers working with TOs (Crawford 1982; Lands 1997; Mangglamara et al. 1991; Paddy and Smith 1987; Rouja 1998; Smith 1997; Smith and Kalotas 1985; Kenneally et al. 1996). More recently the KLC has undertaken ethnoecological work with TO groups initially funded through the Tropical Savanna Cooperative Research Centre. This work has resulted in plant and animal knowledge lists for the Wanjina Wunggurr Uunguu and Balanggarra Native Title Groups including words in Wunambal and Gaambera languages and Belaa and Yeiji languages respectively (KLC 2000). In 2009 and 2010, the Wunambal Gaambera Aboriginal Corporation undertook further work, the results of which were published as a book in May 2011 (Karadada et al. 2011). Belaa speakers have done further work on their lists but this remains unpublished. Worrorra speakers also commenced similar work but their list also remains unpublished.

\section{ABORIGINAL CULTURAL BELIEFS AND VALUES}

Aboriginal peoples' connection to country is influenced by their religious beliefs, long occupation, and an extensive body of knowledge, all of which relate to both extended and more local stretches of country. Traditional Owner beliefs and values have been articulated by various Aboriginal people and by anthropologists (Chalarimeri 2001; Blundell and Woolagoodja 2005; Ngarjno et al. 2000; Mowaljarlai and Malnic 2001). More recently, as noted above, Aboriginal cultural values were documented for assessment for national heritage listing (Blundell and Doohan 2009; Blundell et al. 2009; Crawford 2009; Vachon 2009).

Like Aboriginal people across Australia, Kimberley TOs believe in an era of creation when ancestral beings formed features of the land and the sea, created animals and plants, implanted languages in the country and gave Aboriginal people a set of laws and customs to live by (AHC 2011). Generally glossed in English as the Dreaming', or 'the Dreamtime' (Stanner 1979, 1987), the events of the Dreaming are conveyed through complex religious narratives that Aboriginal people call their 'stories.' Importantly, the events of the Dreaming resonate in the present. Ancestral creator beings continue to inhabit the country where they manifest themselves as rock art, stone arrangements and other tangible and intangible features of the land and the sea. As such, these features provide visible evidence of creative labours of these Dreaming Beings (Blundell 2003). Moreover, as powerful sentient beings, the Ancestral Beings have the capacity to bring good fortune, but also harm to humans and country.

The language groups whose territories are included in the KIBS project have different accounts of the Dreaming as well as different bodies of laws and customs, as reflected by the native title communities. Some 'stories' and some aspects of their law are restricted and secret, particularly parts of the male initiation ceremonies. Other aspects are not restricted in the same way, but are still controlled by rules and protocols of disclosure such as who can grant an outsider permission to visit country.

For members of the Wanjina Wunggurr Community, the Dreaming is 'Lalai'. As was indicated above, this community includes the Dambimangari and Uunguu native title groups (as well as the Wilinggin native title group). Members of these groups are TOs of islands and adjacent waters associated with Worrorra, Gaambera, Wunambal, Yawijibaya, Winjarrumi, Umiida and Unggarranggi languages. Members of the Wanjina Wunggurr Community share a unique set of beliefs and practices including a patrilineal moiety system of political organisation represented by two nightjar birds, and other animal species. In contrast to other Kimberley peoples, they consider themselves to be the descendants of ancestral beings called Wanjina who are responsible, along with the Wunggurr Snake, for the creation of their country and for their particular laws and customs (Blundell et al. 2009). The Wanjina Wunggurr TO, Janet Oobagooma, describes the creation of the Prince Regent River and Saint George Basin through the actions of two Wanjina who appear in Lalai in their animal forms as Rock Cod and Baler Shell (Blundell et al. 2009). As she recounts, in the process of this creative labour, Baler Shell transforms into St Andrew Island, which takes its Worrorra name 'Ngarlangkarnanya' from the baler shell. The other names associated with the island are Gumalamala and Jirinii which are associated with the local historical narrative coming from Wunambal country to the north. Both of these narratives are also associated with the prominent Mt Trafalgar. This is one example of the complex layered meanings that are associated with places within the traditional country. These narratives are embedded in the country and reflect the interwoven nature of people, Lalai and place. 
Another example is St Andrew Island - it is but a part of a rich and textured space that includes river beds, mountains and sea water.

In some of the Wanjina Wunggurr people's religious narratives, Wanjina transform themselves into rock paintings, including some on islands (Crawford 1969). Wanjina appear in these paintings as anthropomorphic figures, characterised by their lack of a mouth (although there are exceptions). These figures have been widely represented in the mainstream media and are depicted by Wanjina Wunggurr people in their contemporary art. There are also paintings in rock shelters on islands in Wanjina Wunggurr territory that are identified as Kaira beings, similar to Wanjina but originating from the sea. One such painting occurs on Bigge Island (Crawford 1968). Wanjina also manifest as features of the landscape and seascape, and they appear in the sky in the shape of the Milky Way. There are also Wanjina and Wungurr that are manifest as stone arrangements, of which there are many on the islands. As well, Wanjina are closely associated with the formation of clouds and the life giving rains that arrive at the end of the dry season, and with the child-spirits of their children which men 'find' in a dream and then pass to their wives. These child spirits, which people refer to as 'wunggurr', reside in the country at wunggurr sites, for example in whirlpools in the sea, stone arrangements on islands and waterholes on land.

The northernmost islands in the KIBS occur in the Balanggarra claim area. 'Balanggarra' unlike other terms of reference, does not have any language, country or so-called 'tribal' connotations. Balanggarra, which means 'one mob together for country,' was chosen as an appropriate term to describe the collective. Members of this claim group have their own narratives regarding the creation of their country and the source of their laws and customs. These accounts emphasize the ancestral Snake Wunggurr, also called Lu, who created the King George Falls. This ancestral Snake resides at Sir Graham Moore Island and in the adjacent waters of the sea. The Balanggarra elder, Matthew Waina, describes how many years ago, some of his grandparents were drowned in this area during a canoe voyage because of strong currents attributed to this Snake. The Balanggarra people's saltwater country includes a reef called 'Rinjii-barda bindingei', located to the north of Cape Londonderry in the vicinity of Stewart Island, where the Dreaming Star 'fell down' to become the highly prized and ritually important pearl shell (Pinctada maxima) (Blundell et al. 2009).

The southernmost island in the KIBS lies in the territory of the Bardi and Jawi native title group, whose members, as we have seen, are connected to areas of land and water associated with the
Bardi and Jawi languages. Like Wanjina Wunggurr people, Bardi and Jawi people have a distinct set of beliefs and practices. Their country is also characterised by a distinct Indigenous cultural landscape and seascape, where various features are said to be the result of the actions of ancestral Dreaming beings. Although TOs are very familiar with these manifestations of the Dreaming or Iniminongoon Jawal, such physical features of the landscape, and seascape, may not be recognised by people outside the cultural group.

Bardi and Jawi people attribute many features in their country to a Dreaming ancestor called Galalong (also spelled Galalang) who also created natural resources in their country as well as many of their laws (Petri 1938/40; KLC 2010). Along with Galalong, there are other ancestral Dreaming beings associated with Bardi and Jawi country. One of them, Loolooloo, associated with saltwater, manifests as a shark that helps guide people if they are in trouble whilst travelling or hunting on sea country (Frank Davey, pers. comm.).

Bardi-Jawi country is also inhabited by the preexisting spirits of Bardi and Jawi children called 'rai' (KLC 2010). While other Kimberley Aboriginal groups have beliefs about the pre-existing spirits of their children, as we have seen in the case of Wanjina Wunggurr people, the expression of this belief among Bardi and Jawi (as well as among culturally similar groups on the Dampier Peninsula) is quite distinct.

Rai comes to you in a dream. Sometimes they make themselves visible to certain people and will leave markers, like tracks in the sand. Rai live near fresh water places and in caves, you have to be respectful when you're near their place otherwise they will get upset. Rai choose who they belong to. When a rai becomes human it takes on certain characteristics and can often be identified by distinct markings on the body. (Frank Davey pers. comm.)

For Bardi and Jawi people, their country, inhabited by rai, constitutes the physical and the spiritual source of their very identity as human beings.

The Mayala claim area consists entirely of islands and the adjoining waters and other features of the sea. In contrast to the other native title claim areas covered by the KIBS, TOs of the Mayala claim area are connected to their island country on the basis of two distinct cultural traditions, rather than one. Some are connected on the basis of the Wanjina Wunggurr culture, while others are connected on the basis of beliefs that are more similar to those of Bardi and Jawi culture. This situation appears to reflect the geographical location of this claim area between the Bardi and Jawi determination area, to its south, and the Dambimangari determination area of Wanjina Wunggur people, to its north. 
Historically, Mayala TOs have had important links with both Wanjina Wunggurr groups and Bardi and Jawi, including intermarriages between their members. Their island country is also strategically located at the nexus of a coastal trading network that has extended along the Kimberley coast and has involved TO traders associated with different cultural traditions. This coastal network is part of a much broader exchange system that continues to operate across the Kimberley region and is known as 'wurnan' to Wanjina Wunggurr people and 'anggarr' or 'rubarn' to Bardi and Jawi people (Blundell and Woolagoodja 2005). In the past, the participation of Mayala people in this coastal network allowed them to obtain mangrove logs required for making the double log rafts (to be described below) that they depended on in order to move from island to island and access the mainland. Logs for making these rafts were obtained either directly or in trade from the large mangrove swamps located on the eastern shore of King Sound in the Dambimangari claim area. The Jawi, on Sunday Island (in the Bardi and Jawi native title determination area), were middle men in this network, trading rafts and raft poles to Bardi based on the Dampier Peninsula mainland; these items were exchanged for spears which were in great demand by island people given the scarcity of suitable woods for making them on the islands (Tindale 1974).

Throughout the survey area, a range of images are found at rock art sites. Islands in Wanjina Wunggurr country contain the world famous anthropomorphic paintings of the Wanjina described above, as well as paintings of other animals and plants, some said to be Wanjina in their animal form. Both Wanjina Wunggurr country and Balanggarra country contain paintings of small, delicate figures that Worrorra people refer to as Gwion Gwion, Wunambal and Gaambera people call Gwion, and Balanggarra people call Girrogorro (Crawford 1968; Ngarnjo et al. 2000). These small lively figures are depicted in scenes that show activities such as hunting. Wanjina Wunggurr people consider the Gwion Gwion to have been put there by a Lalai (Dreaming) creator bird, who is said to have painted the figures with its blood by using its beak, while Balanggarra people consider the figures to represent the everyday activities of their human ancestors (Blundell et al. 2009).

The Wanjina and Gwion/Girrogorro rock art was the subject of a proposal for World Heritage listing in the last decade; however, this proposal was rejected by TOs because they believed that such a listing would disconnect these sites from their broader cultural/country context. For them, rock art sites are components of their broader cultural landscape and seascape (and their sky-scape) (cf. McNiven and Russell 2005). In contrast, the recent listing of the West Kimberley on the National Heritage List, described above, was supported by TOs because the listing recognises the broader Wanjina Wunggurr cultural land- and sea-scape of which this rock art is a part (AHC 2011).

In addition to rock art sites, islands contain scatters of stone tools and middens as well as stone arrangements, some of which are sacred manifestations of Dreaming beings while others are the foundations of shelters or windbreaks (Blundell 1975; O'Connor 1987). There are also engravings and burial sites on islands which are of great significance to TOs. According to senior men and women the islands have been used on a seasonal basis for hunting turtle, collecting turtle eggs and harvesting vegetable foods. Elders also talk of 'blackfella roads' (morr in Bardi, and mayirri in Jawi [Bowern 2008]), walking trails that connects camping areas and water places on islands. Across the saltwater countries of West Kimberley people, there are also sites that relate to contacts between Aboriginal people and outsiders that figure in Aboriginal people's oral accounts of their history. Through time, places become marked through the ceremonial as well as the more mundane practices of TOs: an island in the Dambimangari claim area is now known by the name of a Worrorra woman who is buried there (Love 1938), while another spot is referred to as the place where a Worrorra man 'lost his glasses' a few years ago.

\section{CARING FOR COUNTRY}

While members of the native title claim groups have different beliefs and practices, they all have a deeply felt responsibility to maintain the spiritual health of their countries. Because the country is perceived as sentient and alive, it is important for TOs to regularly 'visit country'. Country that is not regularly visited by its TOs is said to 'get lonely' or in the case of shelters and caves along estuarine river systems, 'hide themself' from TOs.

Caring for country involves landscape scale burning during the dry season to facilitate the growth of fresh vegetation with the arrival of the annual rains. During bush trips, TOs will clean away the overgrowth at places such as the graves of deceased relatives. Such activities are said to keep the country 'bright.' For Wanjina Wunggurr people, caring for country includes 'freshening' (i.e. repainting) the Wanjina who have 'put themselves' as paintings across their homeland (Blundell and Woolagoodja 2005). Arriving at a painted site, TOs 'call out' to alert the Wanjina of their visit before repainting their fading images. Bardi and Jawi and Mayala people talk to the 'rai' places that are inhabited by 'rai spirits'. 
In all the claim areas described above, islands are inhabited by the spirits of deceased ancestors and by the Dreaming ancestral beings. In the case of the Worrorra people, the last place where the deceased 'foot touches ground' before entering the afterlife is an island. There are culturally specific rituals that must be followed so as not to offend these resident spiritual beings. For example, when they arrive at islands, Aboriginal people call out to announce their arrival and then perform other rituals to ensure a safe visit. Strangers, or TOs who have been absent for a while, undergo a ritual whereby they walk through smoke produced by placing green leaves or certain kinds of seaweed on a small fire. It is imperative that strangers to a country be introduced in this way; the smoke is said to eliminate strange scents from the visitors which allows the country to recognise them. As the Balanggarra TO, Neil Taylor, stated:

A lot of old people used to walk around here before, on the side of this beach, in this country. So when strangers come here...they got to get smoked by smoke fire...so they don't get sick walking around in the bush, you know. That's why we put everyone through the smoke, so no one can't dream about the old time, the olden day spirit make them silly in the head.

'Caring for country' is a reciprocal relationship between TOs and their spiritual beings. In the case of outsiders, it requires the asking and giving of permission by the appropriate TOs in order to access a particular area and the resources in it. Some areas are dangerous or restricted to outsiders and cannot be visited, such as law grounds, certain cultural sites, and burial grounds. A late Ngarinyin elder, a member of the Wanjina Wunggurr community, wrote about an island off Champagney Island called 'Libudbud Udman Ngirri Ngari'. This island is considered a portal to 'Dulugun', the home of dead spirits for members of his community (Mowaljarlai and Malnic 2001; cf. Lommel 1997 viz 1952). The island is a dangerous place where people should not visit (K. Oobagooma ${ }^{\dagger}$, pers. comm.). There were many instances during the KIBS project when TOs identified important cultural sites on islands that the survey team needed to avoid or only visit if accompanied by a TO. Sylvester Mangolamara and Sylvia Djanghara spoke of the importance of burial sites as well as Wanjina rock art on Bigge Island. Terry McCarthy spoke of law grounds on Sunday Island that teams needed to avoid. Rai spirits found in both the Bardi and Jawi and the Mayala claim areas can cause trouble for strangers who visit or camp in the wrong place, or visit these claim areas without being introduced in the proper way.

\section{ACCESS TO ISLANDS, OCEAN TRAVEL AND NAVIGATION}

On the north-west coast from One Arm Point and Sunday Island to Napier Broome Bay, rafts made from logs cut from the trunks of the Kapok Mangrove tree, Camptostemon schultzii, were widely used for water travel in the sea (Vachon 2009; Love 1936; Tindale 1974). Bardi, Jawi, Umiida, Ungarranggu, Worrorra, Yawijibaya, Winjarrumi, Wunambal, Gaambera and possibly Kwini people utilised a raft made up of two overlapping raft platforms, referred to as a 'double-raft' in the literature (Akerman 1975; Love 1936) and catamaran by some Aboriginal people. Names for the raft vary between languages: gaalwa (Bardi - Aklif 1999; Kevin George, Angus and Stumpagee families, pers. comm.), Biel Biel/biyal biyal (Jawi), galam/ galum (Worrorra) (Love 1936; Akerman 1975), walawa/bililu/wurndala (Wunambal, Capell 1941; Karadada 2011) and wundana (Belaa) (Dolores $\mathrm{Cheinmora}^{\dagger}$, pers. comm.). Mayala people describe another raft called a munjilal/manjilal kalwa of the same design but larger, lighter, and more buoyant, made from mangrove trees (probably also Camptostemon schultzii) harvested at a particular location in Talbot Bay. Rafts often became sodden with water after a journey and needed to be brought ashore to dry but the munjilal kalwa did not. A wooden paddle made of cypress pine was used to propel the raft, but long distance journeys relied on tides and currents to carry the raft. Saltwater people are proud of their detailed knowledge and particular skills that allow them to navigate the massive tides and often treacherous coastal regions. For instance, Bardi people have a detailed knowledge and classification system of tides that enabled them to navigate some of the most treacherous waters in Australia by raft (Smith 1997; Rouja 1998). This knowledge continues to assist them today. According to Daphne Wilfred, there are names for the passage ways through the islands that enable her people to avoid dangerous whirlpools. They also use the stars to navigate during the night. The detailed cultural knowledge of the tides is expressed in 'Ilma' the traditional song and dance practice of Bardi and Jawi people.

In the north-west Kimberley, dugout canoes have also been used for sea travel over the last few hundred years. Evidence suggests that these crafts were initially obtained from Makassans (present day Indonesians) by Wunambal, Gaambera and Kwini people, who later learned to make them themselves (Crawford 2001). Local Aboriginal names for canoe (namandi, barrawar, barrawara, barrawal, jirraarri) are similar across language groups. Canoes are known to have been made from a variety of native tree species including Bombax ceiba, Nauclea orientalis, Canarium australianum, 
Melaleuca spp., Brachychiton diversifolius, Alstonia actinophylla and Ficus racemosa (Crawford 1982, 1983, 2001; Karadada et al. 2011). Later, during the 1900s, canoes were also adopted by Worrorra people at Kunmunya Mission (Love 1936), Yawijibaya at Montgomery Reef and later by Bardi, Jawi, Umiida and Unggarrangi people around Sunday Island Mission, who call them barrawar (Aklif 1999; Daphne Wilfred, pers. comm.). Canoe journeys by Wunambal, Gaambera and Worrorra people have been documented, including journeys of up to 50 $\mathrm{km}$ offshore to reefs such as Holothuria Reef and Cassini and Troughton islands (Basedow 1918; Lommel 1997; Crawford 2001).

In some circumstances, canoes have some advantages over rafts; they are more manoeuvrable, less susceptible to the influences of the tides and wind, less prone to water logging, can be paddled further offshore, and can carry up to 10 people. However, they are less stable than rafts, sometimes fill with water and can capsize in rough weather and tidal currents (Love 1936; Crawford 2001; Daphne Wilfred, pers. comm.).

In the Cambridge Gulf area, Aboriginal accounts suggest that people did not commonly have rafts or canoes but typically swam across estuarine channels using buoyant logs and assisted by tides, or waded across shallow sandbars at low tide. Balanggarra elders, George Dixon and Selwin Meehan (pers. comm.) have described how, on several occasions in their youth, they accompanied old men swimming across from Forrest River Mission to Adolphus Island to hunt flying fox which roosted on the island in great numbers. They would select a dry buoyant log of any kind to aid them in their swim. This method of crossing Cambridge Gulf was commonplace. Green (2008) has stated that there are instances in which rivers have been forded at low tide with the support of a $\log$ on which infants and dogs have been balanced. Green (1988) provides two further accounts of Forrest River people crossing tidal waters and the hazards of crocodiles. In one account a woman gave up the dog she was carrying to a crocodile to save herself.

In 1925, a woman named Ungala crossed the Forrest River to gather lily-seeds at some lagoons. When she tried to cross back to Bremlah the tide was in. She got a small log with little roots at one end, placed her paperbark parcel of lily roots and seeds on the root end, and her pup on top. Pushing the loaded log in front of her, she started across. Near the middle of the river, a crocodile appeared. Ungala calmly waited until he came up, and then gave him the pup and continued on. When she reached the other side she cried for her pup.

Flying Fox Island was a popular place for collecting crocodile eggs as well as getting the fruit bats for cooking. One Saturday a party of mission boys, some twenty in number, went down the Forrest River to hunt for crocodile eggs. The tide was low as they crossed a sand bank to a small island. They found a nest of crocodile eggs and at once made a fire and had a feast. While they were feasting the tide rose, and when they started homewards the water was already waist high. They joined hands for safety, and shouting to keep off the crocodiles they entered the water. The crocodile whose nest they had robbed, however, was awaiting them. She attacked the boy at the end of the line, but he succeeded in beating her off. She at once went along the line and caught, by the calf of the leg, a lad named Eura. With great coolness he succeeded in getting his hand in her mouth, and caught her by the tongue. She let go, but pulled the muscle of his leg out in a loop. It was a nasty wound. He also had his hand badly cut.

The explorer Basedow (1925) suggests that this simple mode of water crossing was widespread across northern Australia:

The simplest type of float is no doubt the log of light timber used along the north and north-east coast. The straight trunk of a mangrove is selected, and from it a $\log$ is cut, about five or six feet long, which is stripped of its branches. Where a river or estuary has to be crossed, such a log is slipped into the water and the native lays his body over it, lengthwise with his legs straddling it...

Senior Aboriginal men and women do not live in fear of crocodiles. Balanggarra elder Mary Taylor spoke of how her father and her husband would speak to the crocodile in Aboriginal language and tell it not to harm them, before swimming across Cambridge Gulf or across to islands. Similarly, Worrorra elder Janet Oobagooma, whose wunggurr child spirit is the saltwater crocodile, was also taught by her elders to speak to crocodiles and tell them not to cause harm. Sylvester Mangolomara spoke of how his grandfather taught him to speak to crocodiles:

I swear at him in language, then I tell him 'you're not the boss, I'm Wunambal, you're Wunambal'. Then I look him in the eye, and he duck down and take off. He listen. This country not only from him.

Saltwater crocodiles are also considered food and were sometimes hunted from raft or canoe (Jack $\mathrm{Karadada}^{\dagger}$, pers. comm.).

\section{OCCUPATION OF ISLANDS}

Aboriginal occupation of islands has ranged from permanent occupation of some of the larger islands, to seasonal occupation of accessible islands, to occasional visits to some of the smaller and more remote islands. Evidence for occupation comes largely from the accounts of TOs and from archaeological evidence. 
O'Connor (1989) has remarked on the paucity of shell middens and scattered artefacts on islands in the Buccaneer Archipelago, despite the long occupation of many of the islands. She concludes that Aboriginal people mostly camped on beaches where camp remains have been removed by the influence of large spring tides. The exceptions are Macleay Island and High Cliffy Island which have significant numbers of artefacts and Koolan and High Cliffy Island which have rock shelters with rich deposits from human occupation. There is similar evidence on the Maret Islands and TOs talk of ceremonial activities and large occupation camps on Bigge Island. Further north, Sir Graham Moore Island is also known to have a significant shell midden (Matthew Waina, pers. comm.).

For some TOs their country has been focused on particular islands and these people have been considered 'island people.' There is evidence to suggest that in the past such 'island people' spoke distinct languages or dialects and had particular ritual and ceremonial activities that were specific to being saltwater and island people. According to some researchers, in the past Sunday Island (O'Connor 1989), Montgomery Islands (Tindale 1974; O'Connor 1989), Champagny Island, Augustus Island, Bigge Island and Sir Graham Moore Island (Crawford 1983) sustained semi-permanent populations and were associated with particular clan groups. These larger islands have permanent water and rich resources that supported such populations. For some TOs, their country has consisted of both islands and mainland areas; for instance Bigge Island and the Maret Islands are part of a larger single 'country' that extends onto the mainland. There has been movement of people between island and mainland groups, with intermarriage and trade of goods and culture (Blundell 1975; Crawford 2001). During an archaeological survey of island countries in the Montgomery Islands area, Blundell was told by a senior Worrorra man that the Yawijibaya, the local group connected to the Montgomery Islands ran a 'school' for mainland Worrorra boys, teaching them how to exploit the abundant marine resources of the area (Blundell 1975).

Other smaller islands could only be accessed seasonally, dependent on the availability of permanent fresh water and food. Crawford (1983) has described how Wunambal and Gaambera people living on Cape Voltaire and Cape Bougainville were able to seasonally access islands and reefs by canoe, but with some socially derived constraints as well as seasonal influences. Many islands lack permanent fresh water and strong south-east winds in dry season months effectively closed the seas to canoe travel. For this reason, canoe voyages were made as short raids on resources while families remained camped on the adjacent peninsulas. Voyages were typically undertaken during neap tides each fortnight, in order to avoid strong currents. The voyages targeted resources like turtle eggs on nesting beaches, sea turtle and dugong on reefs, and yams and root crops collected at the end of the wet season. Fruit bearing trees are abundant on some of the offshore islands and, along with birds and marine animals, provided a major incentive for visiting these islands in the wet season (Blundell 1975). Once the dry season arrived and the seas became inaccessible, coastal groups would move inland to join inland groups hunting kangaroos with fire and collecting freshwater resources. The same pattern has been documented for other groups (Kwini - Crawford 1982; Worrorra - Blundell 1975). This seasonal movement of people to utilize different rich food resources also allowed for intermarriage and ceremonial exchange (Blundell 1975). Traditional Owners continue to spend time on these islands, visiting them, setting up camps, performing ceremonies and accessing resources. This ongoing use and occupation of islands has been formally recognised, leading to the Bardi and Jawi, Dambimangari and Uunguu native title determinations.

\section{WATER SOURCES ON ISLANDS}

The availability of fresh water, which varies across islands, has been one of the principal constraints on the extent to which islands can be used and occupied by Aboriginal people. Some islands have permanent and reliable sources of fresh water while other islands have ephemeral water or no water at all. Augustus Island has some large creek systems which flow part of the year and retain permanent pools. Sir Graham Moore Island has a freshwater pool on its north side that has waterlilies and seepage on the southern side (Crawford 2001). These water sources may have suffered some degradation from tidal surge and lack of fire allowing them to be overgrown with vegetation (Matthew Waina, pers. comm.). Many of the islands have freshwater springs that are covered at high tide and exposed when the tides are low. Mr Jack Karadada ${ }^{+}$has explained how he placed standing stones above the tide line as markers of these sites.

Bardi and Jawi people describe a number of types of fresh water (Aklif 1999). Oomban are freshwater seepages that flow in the intertidal sands and can be dug up at low tide but are covered by the sea at high tide. Oomban occur on most islands and provide drinking water to birds (Daphne Wilfred, pers. comm.). Iidarr are creeks, the majority of which are largely ephemeral on islands but in some cases can flow much of the year; biidin is water that 
can be dug just below the surface in creeklines and depressions; oongoor is rainwater that collects in flat rockpools; and niimid is rainwater in deeper rock pools. A number of larger islands have 'oola' - permanent water sources (Kevin George, Angus and Stumpagee families, pers. comm.). Emergency water can also be obtained from the raw white meat of the giant clam.

As Crawford (1983) outlined above, in Wunambal and Gaambera country, many offshore islands could be reached by long voyages on canoe or raft to exploit marine resources on the surrounding reefs but the islands had limited fresh water. Where water was not available, people survived for a few days on water carried on board inside baler shells and also by obtaining moisture from marine turtle eggs.

The availability of fresh surface water is likely to affect the occurrence of some species on islands. According to Worrorra elder Victor Barunga ${ }^{\dagger}$, the permanent pools on Augustus Island support aquatic species like freshwater crocodiles (Crocodylus johnstonei) and freshwater (chelid) turtles and waterlilies. Large animals like kangaroos, emus and dingos are dependent on regular access to drinking water. Agile wallabies (Macropus agilis) are able to survive by accessing fresh water in the intertidal areas at low tide or by drinking sea water and thrive on some islands like Adolphus and Mary Island where water is not permanent.

Knowledge of the location of freshwater places and their names is an important component of the traditional knowledge of Aboriginal people. Many freshwater places are culturally important sites associated with the Dreaming and are a source of 'spirit babies' that are important for conception (AHC 2011). Aboriginal people believe that when strangers visit these water places without being accompanied and welcomed by TOs the water sources can dry up. Mayala people emphasize that in their country some waterholes need to be maintained by removing mangroves, vegetation and sediment to restore their flow or to expose the water.

A freshwater spring on the south side of Augustus Island has a long history of use by both Aboriginal people and various visitors. Dambimangari people call it Aagungarlangarlangarri in Worrorra, which translates as 'talking water' in English (Aagu = water, ngarla = talk, -ngarri = associated with) (Love 1936; Heather Umbagai ${ }^{\dagger}$, Janet Oobagooma, pers. comm.). A Makassan fleet was documented taking water from here in 1865 (Crawford 2001). Worrorra people revealed its location to the Camden Harbour settlers under some duress in the 1860s (Crawford 2001). Bishop Torres visited it on his voyage and suggested it was shown on a navigation chart in 1906 (Perez 1986). It was also used by pearl luggers into the 1920s (Basedow 1918). Janet Oobagooma (pers. comm.), who lived on the island as a child, said the spring used to have a hollow log acting as a pipe to make it easy for luggers to collect water but this has now gone.

\section{FOOD ON ISLANDS}

Island people identify themselves as 'Saltwater People' relying predominantly on rich marine resources like turtle, dugong, fish and shellfish for much of their diet, and camping close to the sea (Crawford 1983; O'Connor 1989). However, islands also hold some important terrestrial food like edible plants, sugarbag and flying fox that have been seasonally harvested or taken opportunistically.

In the past, rafts and canoes allowed men to hunt sea turtle and dugong on reef systems in the Buccaneer Archipelago, Montgomery Reef and around offshore islands (O'Connor 1989). These areas continue to be prime locations for the contemporary hunting and fishing practices of TOs. During lalin, the turtle breeding season (October to December), green turtles aggregate and mate at certain places around Sunday Island. Jawi people have vantage points on the island where they can watch the loo, tidal current, for mating turtles (Kevin George, Angus and Stumpagee families, pers. comm.). Sea turtles lay their eggs on many islands, and both nesting females and their eggs can be harvested at this time. Marine turtles also lay their eggs on island beaches and are important foods for Aboriginal people (Green 1988). Flatback turtles tend to favour inshore islands and mainland beaches while green turtles favour offshore islands with clearer waters (Karadada et al. 2011).

Shellfish like trochus, giant clam, oysters, baler shell and trumpet shell are abundant on some reefs. Aboriginal people know how to use fish poisons made from certain plants (e.g. Tephrosea rosea) to harvest fish in rock pools at low tide (Kenneally et al. 1996; Karadada et al. 2011). Fish can also be speared by hand.

Offshore islands are important nesting sites for seabirds and Aboriginal people harvest these eggs in season. Twin Island near One Arm Point has nesting terns, sooty oystercatchers, pelicans and other species (Akerman 1985; Hassell and Boyle 2002). Bardi and Jawi people still visit these islands to harvest seabird eggs in AugustSeptember (Terry McCarthy, pers. comm.). Seabird eggs, namely boobies and terns, were harvested on the Montgomery Islands by Yawijibaya people and taken as gifts to mainland people (Love 1936; Blundell 1975). Wunambal and Gaambera people have also visited a number of islands during Yirrma, the south-east wind time (approximately 
TABLE 2 Some plant foods specifically identified by Traditional Owners as being locally important on particular islands. Table 3 provides a more comprehensive list of plant species recorded in the KIBS on islands and known to be used across these language groups generally.

\begin{tabular}{|c|c|c|c|}
\hline Species & Language names & Islands & Sources \\
\hline $\begin{array}{l}\text { Buchanania obovata 'green plum' } \\
\text { (including fruits and roots) }\end{array}$ & $\begin{array}{l}\text { Gorrol (Bardi) } \\
\text { Kuleyi (Balanggarra) }\end{array}$ & $\begin{array}{l}\text { Long } \\
\text { Sir Graham Moore }\end{array}$ & $\begin{array}{l}\text { Daphne Wilfred } \\
\text { Matthew Waina }\end{array}$ \\
\hline Vitex glabrata 'blackberry' & $\begin{array}{l}\text { Kukulangi/kulangi (Balanggarra) } \\
\text { Gulangi (Wunambal) }\end{array}$ & $\begin{array}{l}\text { Sir Graham Moore } \\
\text { Bigge }\end{array}$ & $\begin{array}{l}\text { Matthew Waina } \\
\text { J. Karadada }\end{array}$ \\
\hline Persoonia falcata 'bush pear' & Kandala (Balanggarra) & Sir Graham Moore & Matthew Waina \\
\hline Mimusops elengi 'bush jaffa' & $\begin{array}{l}\text { Joongoon (Bardi) } \\
\text { Yangkowii (Wunambal) } \\
\text { Walarra (Wunambal) }\end{array}$ & $\begin{array}{l}\text { Widespread } \\
\text { Long } \\
\text { Bigge }\end{array}$ & $\begin{array}{l}\text { Daphne Wilfred } \\
\text { J. Karadada } \\
\text { Aklif (1999) }\end{array}$ \\
\hline Flueggea virosa 'white currant' & Goorralgar (Bardi) & Widespread & Aklif (1999) \\
\hline Ficus leucotricha & Goorrir (Bardi) & $\begin{array}{l}\text { Sunday } \\
\text { Jackson } \\
\text { Long }\end{array}$ & Aklif (1999) \\
\hline $\begin{array}{l}\text { Ficus platypoda, } \\
\text { F. atricha }\end{array}$ & Barramanbi (Wunambal) & Bigge & $\begin{array}{l}\text { J. Karadada } \\
\text { Karadada et al. (2011) }\end{array}$ \\
\hline Syzigium eucalyptoides & Iilarr (Bardi) & High & Aklif (1999) \\
\hline $\begin{array}{l}\text { Terminalia ferdinandiana } \\
\text { 'billygoat plum' }\end{array}$ & $\begin{array}{l}\text { madoorr (Bardi) } \\
\text { arrangoor (Jawi) }\end{array}$ & $\begin{array}{l}\text { Sunday } \\
\text { Long }\end{array}$ & $\begin{array}{l}\text { Monty Wilfred } \\
\text { Aklif (1999) }\end{array}$ \\
\hline Terminalia petiolaris & Marool (Bardi) & Long & Aklif (1999) \\
\hline Aidia racemosa / Carallia brachiata & Dumulinggu (Wunambal) & Bigge & $\begin{array}{l}\text { J. Karadada } \\
\text { Karadada et al. (2011) }\end{array}$ \\
\hline Canarium australianum & & Long & Monty Wilfred ${ }^{+}$ \\
\hline
\end{tabular}

May to August), to harvest seabird eggs (Love 1936; Crawford 1983).

Little corellas nest in rocky crevices on several islands in the Buccaneer Archipelago including Jawinarr (the Tryer Islands Group) and rocky islands near Long and Mermaid Islands.

\section{IMPORTANT PLANT FOODS ON ISLANDS}

Islands have a wide variety of edible plant species. A comparison of the KIBS species list with documented Aboriginal food species shows there are some 126 species, subspecies and varieties across the 24 islands in the survey (Tables 2 and 3). However, prior to the introduction of motorised watercraft the exploitation of these plant foods would have depended on whether the islands could be accessed when the foods were in season and the availability of other foods. Use of different plant species also varies somewhat between Aboriginal groups. There are examples of islands being seasonally accessed to harvest rich plant resources, particularly yams and bush fruits. In other situations plant foods have been accessed opportunistically to supplement other staples. There is some evidence to suggest that plant resources have been managed by Aboriginal people and that the distribution and abundance of some species is a product of this management (Hynes and Chase 1982). This management has included the use or exclusion of fire, replanting of yams and the deliberate or inadvertent spreading of seeds (Vigilante 2004). 


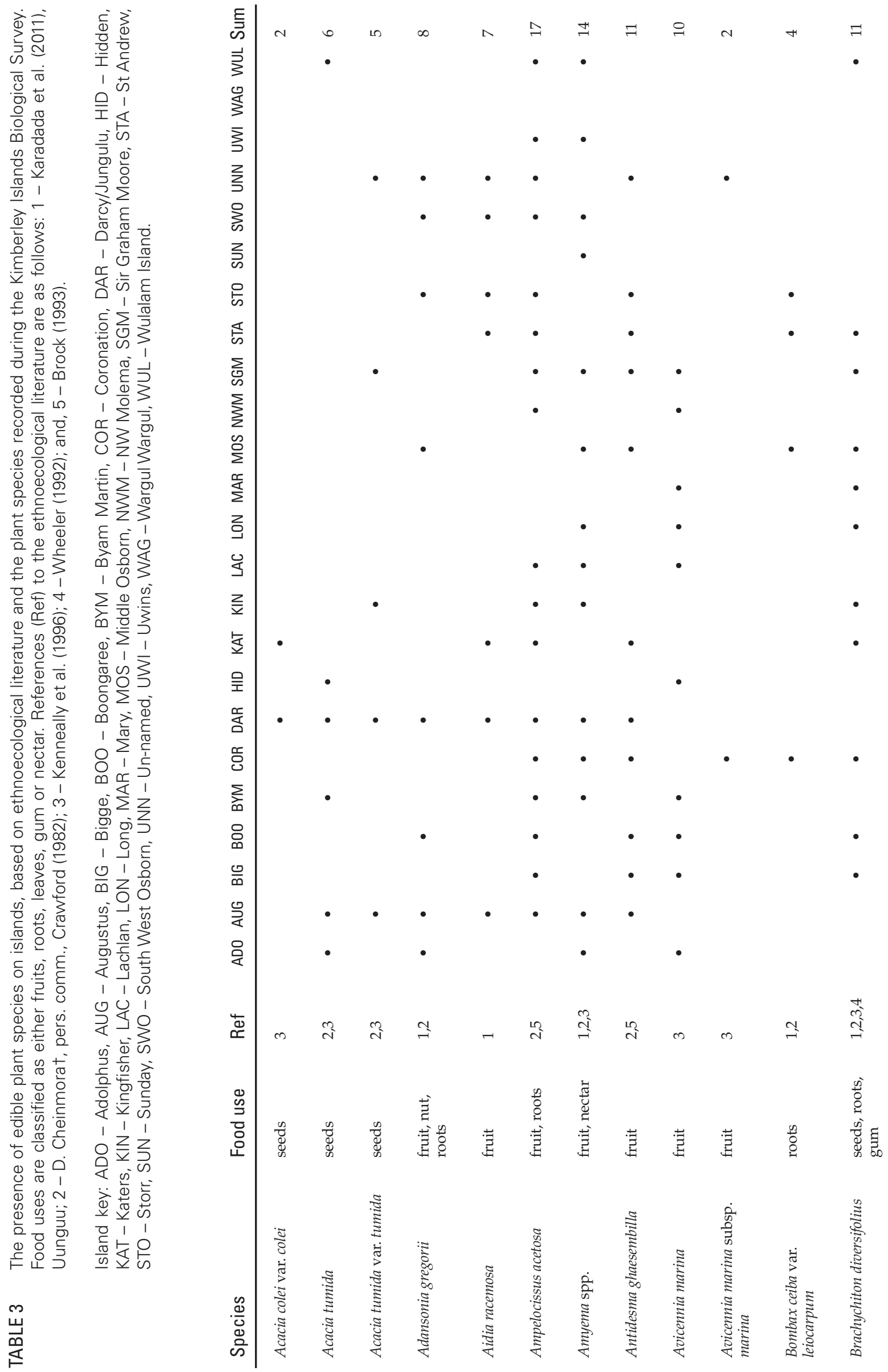




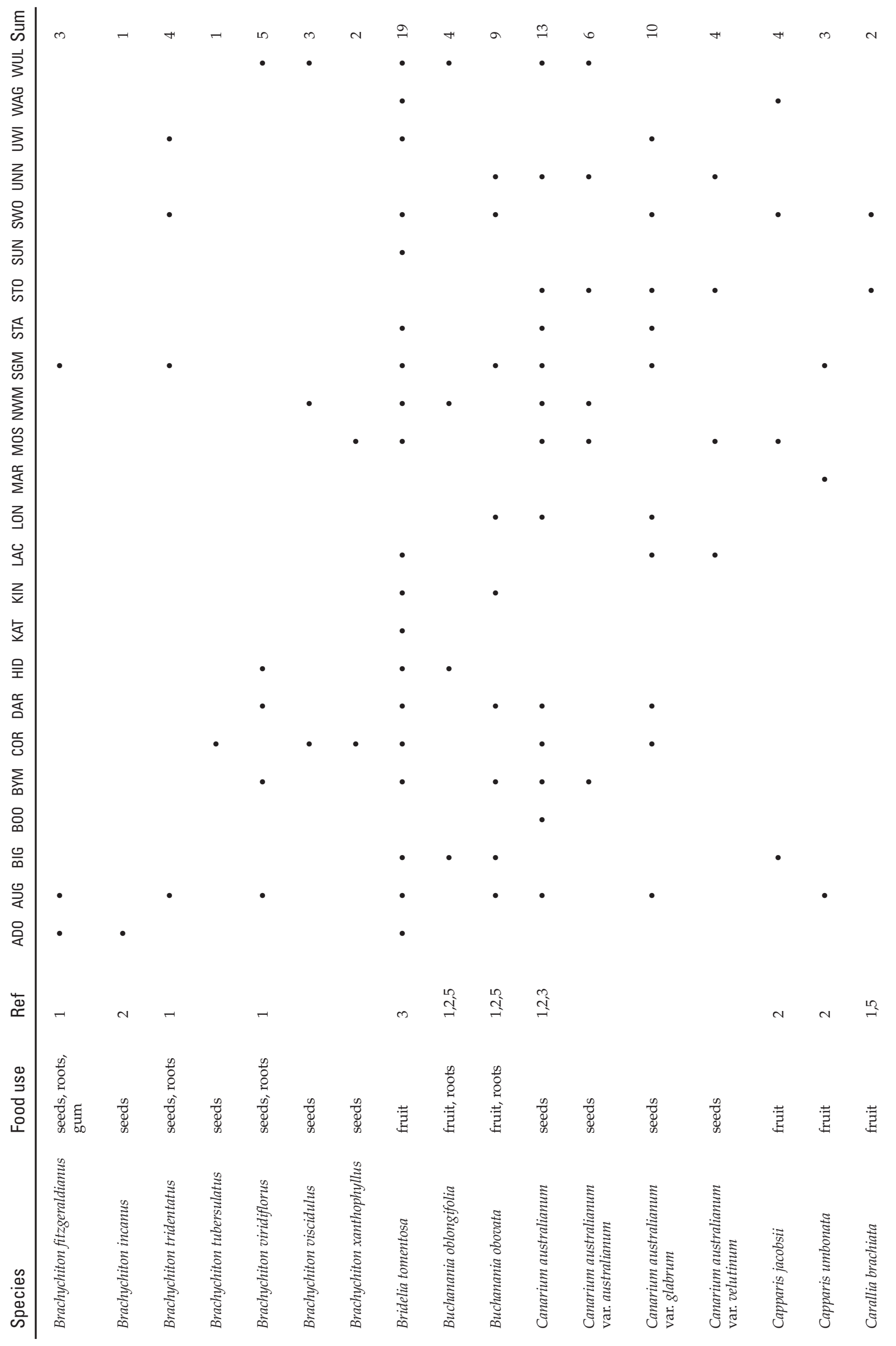




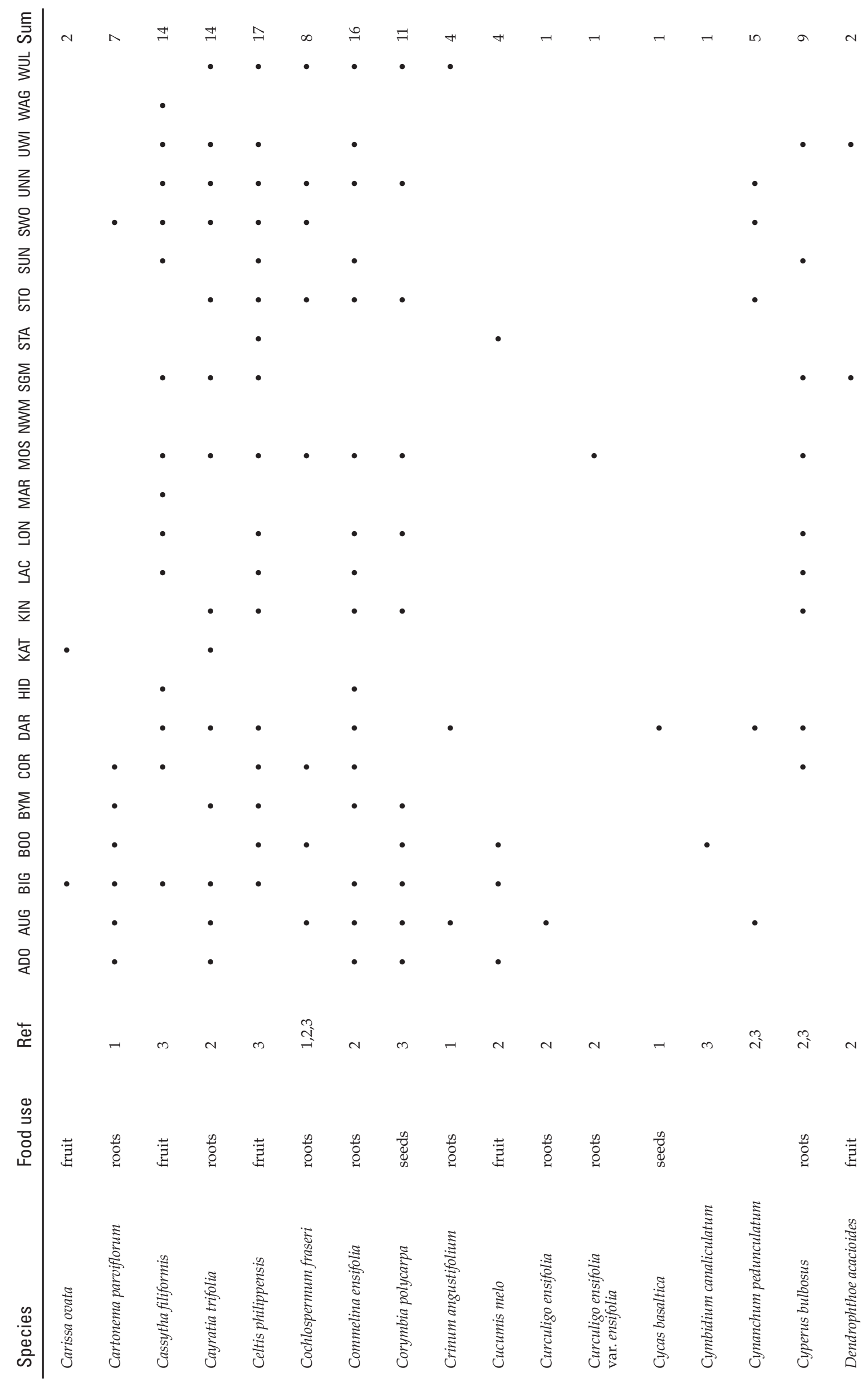




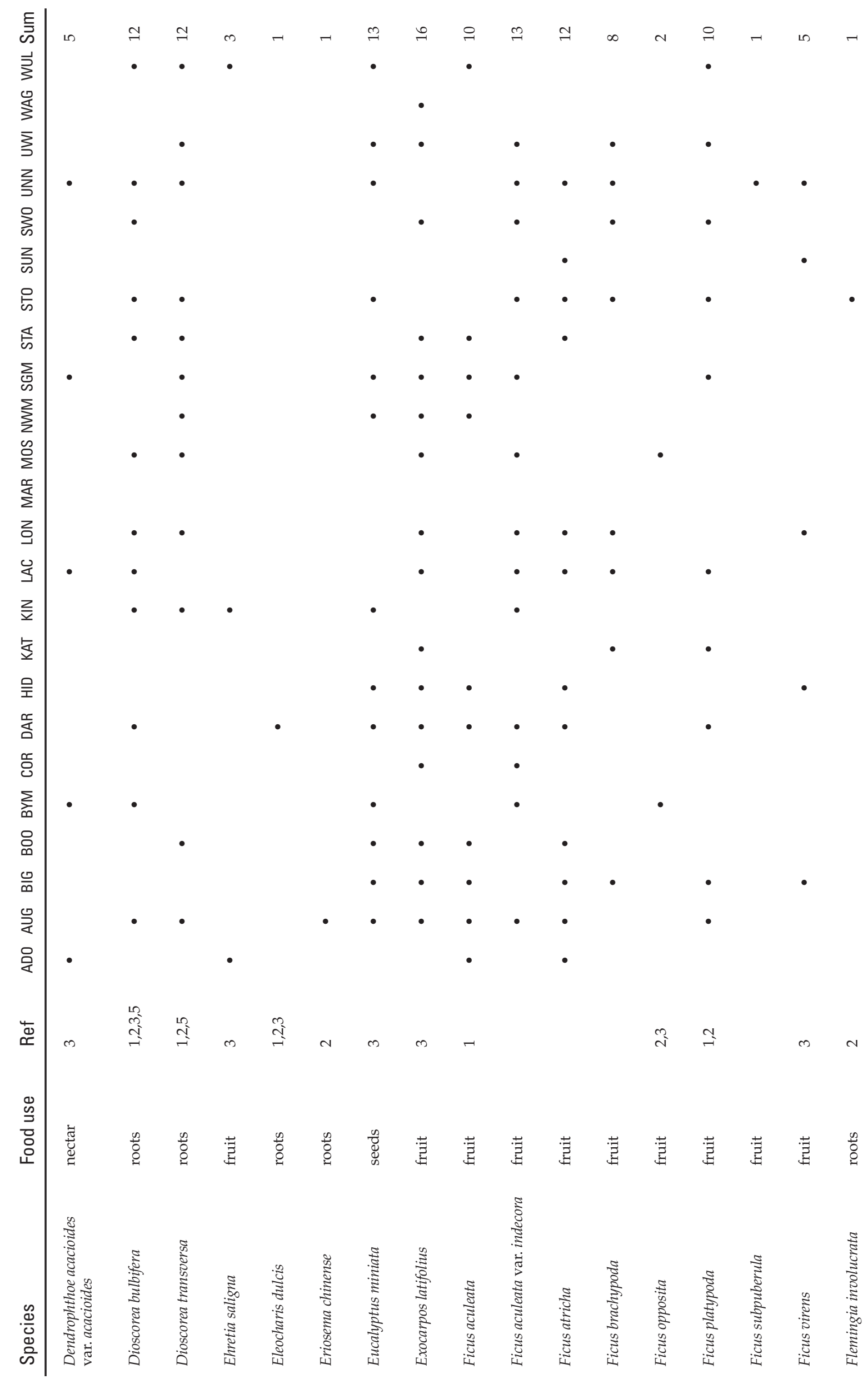




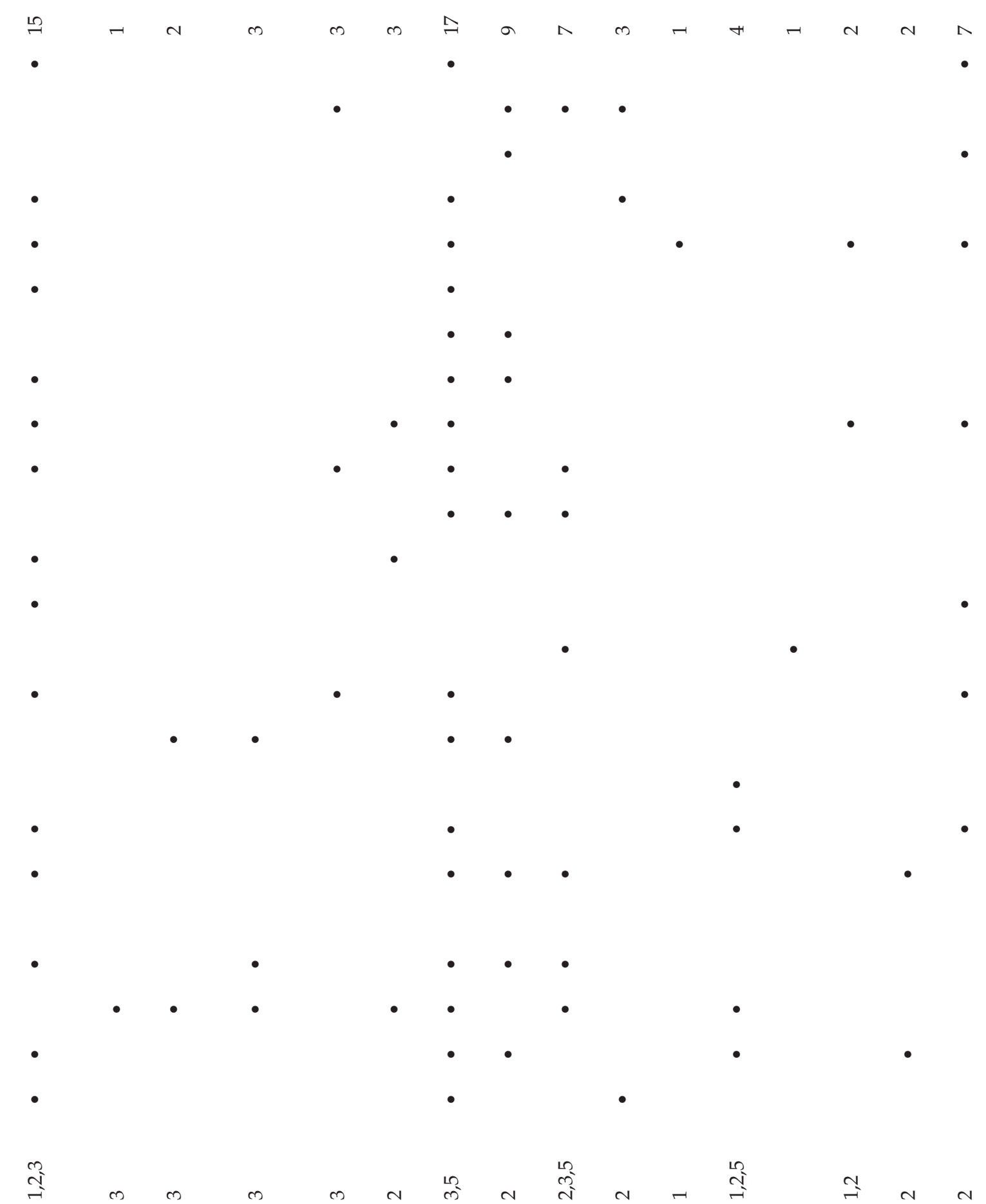

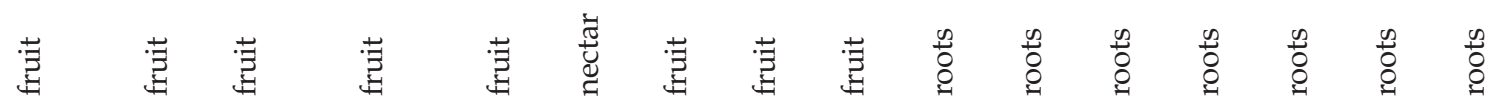

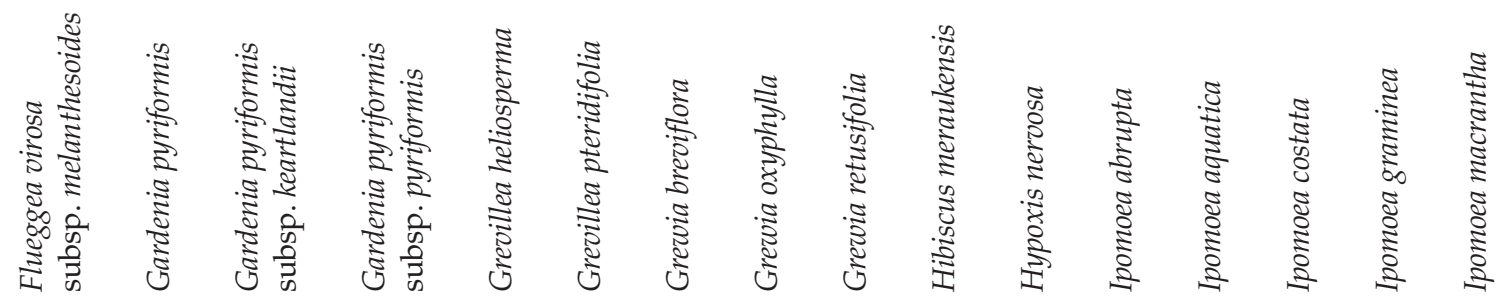




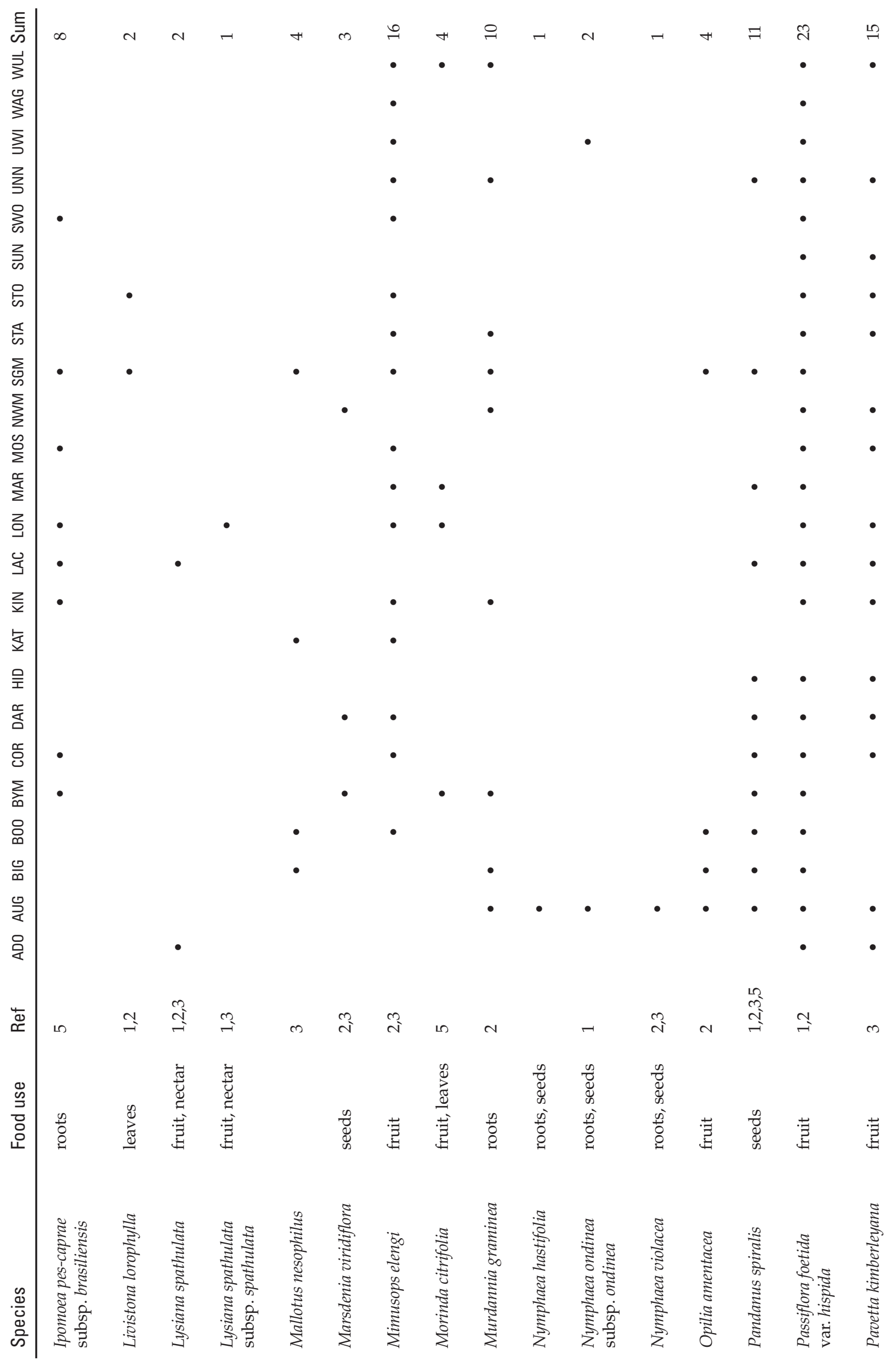




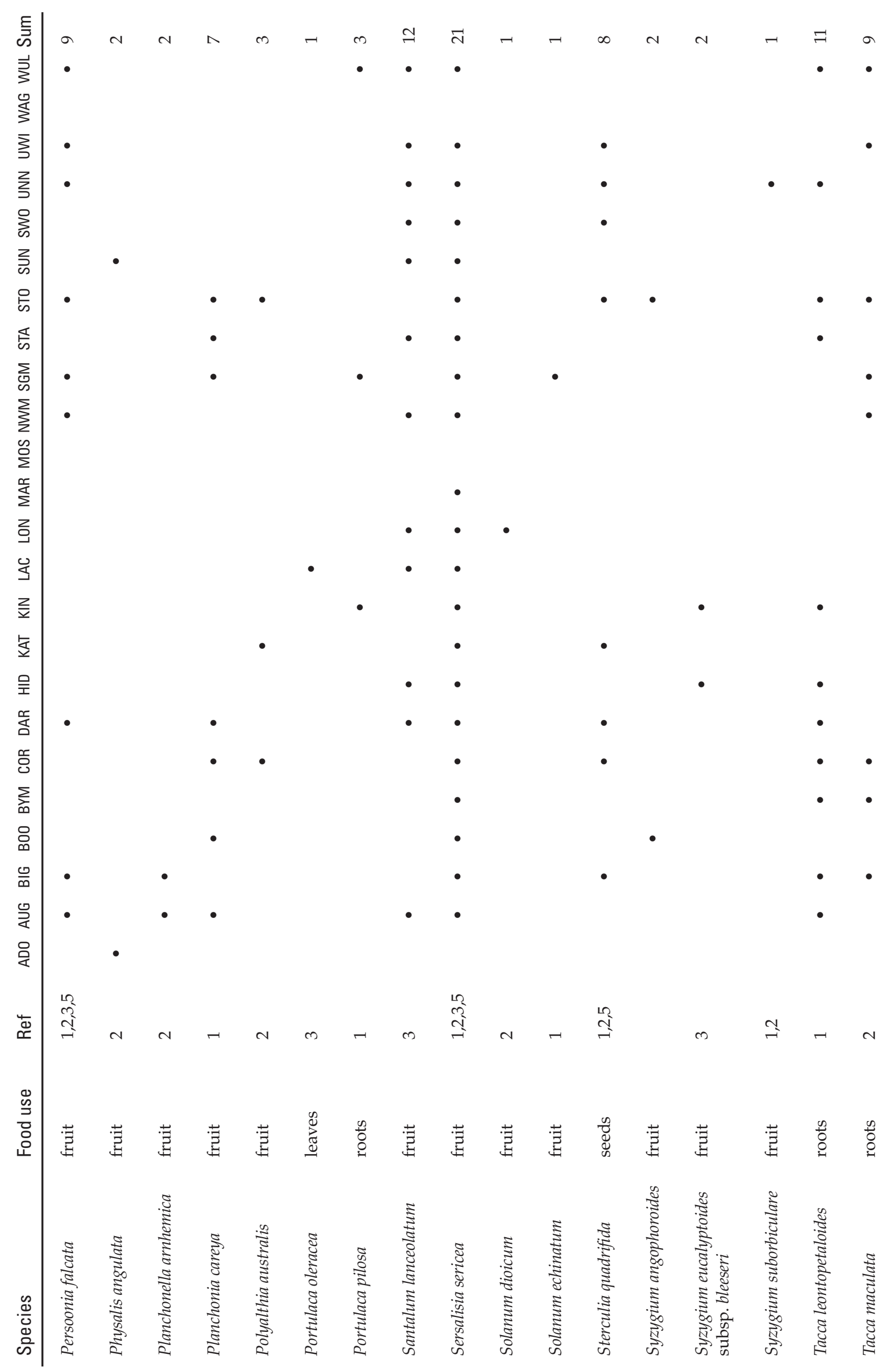




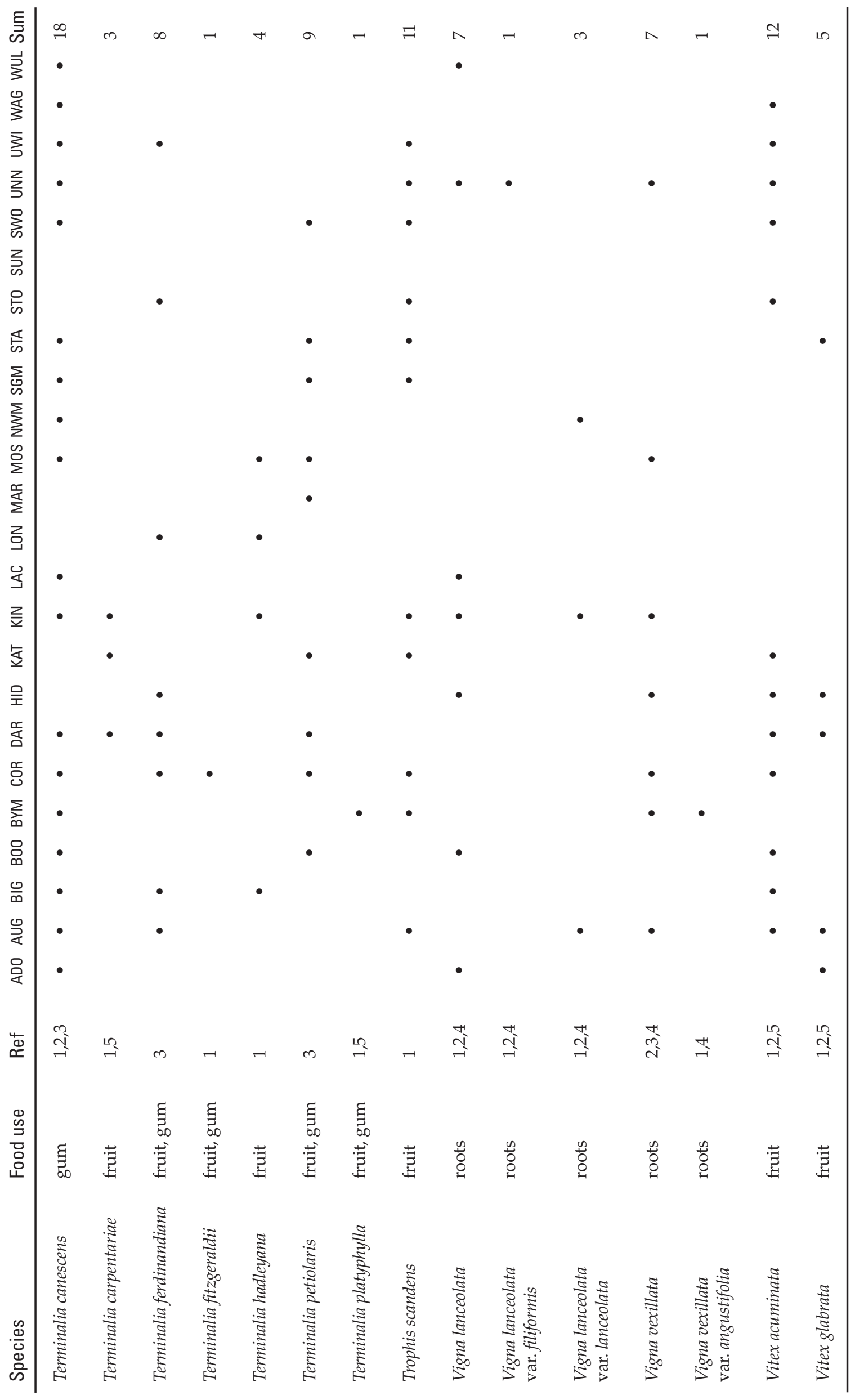


The long yam Dioscorea transversa, widely known as garnmanggu in Worrorran languages or goolngarriny in Bardi and Jawi, is one of the most important staple root foods for North Kimberley Aboriginal people (Love 1936; Crawford 1982, 2001; Aklif 1999; Karadada et al. 2011). In some cases, islands have been visited especially to harvest this yam (Green 1988). The long tuber is dug up in the dry season and roasted in hot coals. The unripe seed pod, known as mardilangg in Bardi and Jawi, can also be roasted on hot ashes and eaten in the early dry season (Aklif 1999). This species was recorded on 12 islands in the KIBS, but Aboriginal people say yams are particularly abundant on Long Island in the Mayala claim area, on Bigge, Katers and Mary Island in Wunambal Gaambera country (Vigilante 2004; Jack Karadada ${ }^{\dagger}$, pers. comm.; Sylvester Mangolamarra, pers. comm.) and Sir Graham Moore Island (Matthew Waina, pers. comm.), and on Lacrosse Island (Green 1988) in Balanggarra country. This important resource has been carefully managed by Aboriginal people. They have been mindful not to burn islands before the yams are harvested; otherwise the dry vine is difficult to locate (Vigilante 2004). They also have replanted the apex of the yam to ensure its regrowth (Vigilante 2004). Some 38 other plant species with edible roots were also recorded in the KIBS. Some of these species, while widespread, contain toxins that require special processing before they can be eaten, such as Dioscorea bulbifera, Ampelocissus acetosa, Cayratia trifolia and Crinum angustifolium (Crawford 1982; Karadada et al. 2011). Traditional Owners highlighted some important root crops on islands including irrilm/ aanyjoo (Glycine? sp.) on Sunday Island and Long Island (Aklif 1999; Daphne Wilfred, pers. comm.), niyalboon (Cyperus bulbosus) on Long Island (Aklif 1999), wuningarr (Ipomoea abrupta) and manda (unidentified) on Bigge Island and other Wunambal islands (Karadada et al. 2011; Jack Karadada', pers. comm.) and gunu (Dioscorea bulbifera) on Katers Island (Jack Karadada ${ }^{\dagger}$, pers. comm.).

Some islands are rich in fruit bearing trees and shrubs. The KIBS data records Celtis philippensis, Sersalicia sericea, Grewia brevifolia, Mimusops elengi, and Flueggia virosa subsp. melanthesoides on many islands. Other species, known to be especially important food species (including Ficus, Buchanania, Vitex, Persoonia, Syzigium and Terminalia species), were found to be less widespread but still occurred on several islands. Aboriginal people visited some islands especially to harvest these plant foods in season. As noted above, Blundell (1975) documented that mainland Worrorra people have visited offshore islands especially to harvest fruits including those of two Ficus species, several berry trees, boabs (Adansonia gregorii), native plum tree, pandanus (Pandanus spiralis) and cycads (Cycas sp.).
In the past, Worrorra people often congregated to share in these plentiful island resources during the wet season. Mayala people recognise Long Island as being particularly rich in fruit trees, particularly gorrol (Buchanania obovata), which they were mindful not to damage with fire.

\section{ANIMAL AND MINERAL RESOURCES}

According to TOs, kangaroos and wallabies only occur on a few islands, partly because they are dependent to some extent on fresh water (cf. Blundell 1975). Euros (Macropus robustus) are known to live on one small island adjacent to Hidden Island with permanent freshwater and close to the mainland. Agile wallabies (M. agilis) have the ability to survive without permanent water by drinking freshwater seepages below the tide line (Sylvester Mangolamara, pers. comm.). They are known to occur on Mary Island, Adolphus Island and Sir Graham Moore Island and were recorded on Mary and Adolphus by the KIBS (Sylvester Mangolamara, Matthew Waina, pers. comm.). Rock wallabies occur on a number of islands throughout the region. The Monjon (Petrogale burbidgei) population on Bigge Island is well known. Nabarlek (Petrogale concinna), which occurs on Long Island, is dependent on the few permanent fresh water sources on the island, and one permanent rockhole is particularly important for them (Daphne Wilfred, pers. comm.). They are not known to have been hunted or eaten by Aboriginal people in recent times. In the past, people sometimes captured them and kept them as pets. There is a narrow opening at the northern point of the island where the wallabies can be captured after being chased and driven with loud noises. Elders also say that these rock wallabies are known to sometimes 'go onto the reef at low tide to eat fish'. One elder stated 'we don't burn this island because of these wallabies, but old people used to burn to make signals to the mainland' (Monty Wilfred', pers. comm.).

Balanggarra people used to swim across to Adolphus Island to harvest flying fox from a large colony that roosted in the mangroves (Lionell Mitchell, pers. comm.). Flying fox colonies are also known to roost in mangroves on other islands in the region. Sylvester Mangolamara noted large numbers of flying fox in the mangroves on Mary Island during the KIBS.

Sugarbag, or the honey and larval stages of stingless bees (Apidae), are an important staple food for Aboriginal people and are known to be particularly abundant on some islands, including Coronation Island and a small island next to Augustus Island. There are several types of sugarbag based on different species/genera of bee (Apidae: Trigona melipes, T. hockingsii, T. spp.) nesting in different situations (mangroves, 
termite mounds and tree hollows) (Akerman 1979; Karadada et al. 2011). A sugarbag called malara was described by Kwini people, and is found in the mangrove Avicennia marina on some islands (Dolores Cheinmora, pers. comm.).

Islands are also known as an important source of ochres (iron oxides) and clays used for ceremonial purposes and often traded by Aboriginal people. People have visited the island to collect these ochres and most particularly the highly prized 'greasy red ochre'. The ochre is wrapped in paperbark and traded through the wurnan, the traditional trading system described above. Ochres of different colours can also be found at low tide around islands across the region. The presence of ochre in the landscape is often connected with important Dreaming stories across the region.

\section{FIRE ON ISLANDS}

Historically, islands were burned frequently for a range of reasons including, looking after country (land management), hunting and smoke signals (Vigilante 2004). Aboriginal burning on islands was noted by early explorers to the region (Vigilante 2001). After Aboriginal people moved to settlements in the 1900s islands were no longer frequently burnt and wildfires became infrequent on islands. Fires that did occur were often intense due to fuel buildup. In its use for smoke signals, people on islands and the mainland have used fires to communicate with each other. Bardi and Jawi people call these smoke signals marrj (Kevin George, pers. comm.) or marrya (Aklif 1999) and usually light them in particular places where they are visible and where the fires will not spread. Smoke signals communicate messages about the location or movement of people, requests to visit another group's country, capture of turtle and dugong or emergencies (Kevin George, Angus and Stumpagee families, pers. comm). Janet Oobagooma recalled the use of smoke when she lived permanently on country as a child and young woman: 'When we see smoke on the islands we would make fire too and they would come here and visit'. There are recent examples of Bardi and Jawi and Mayala people breaking down on islands in motor boats and lighting fires to signal for help. In Kalumburu it is still common for families to light fires along the coast to signal to other people where they are. Jawi people have particular places on Sunday Island where they have made marrj, smoke signals, and looked out for other clansmen sending messages from other islands.

Fire and smoke are often used in rituals associated with cultural responsibilities. As described earlier, smoke fires are used to welcome people to country. Smoke fires also prevent people from being followed by ancestral spirits. This is often achieved by placing green leaves on a small campfire; however, in other situations large sections of bush may be burnt. During recent visits to the Maret Islands, talking about the Wunggurr (ancestral Snake) Wunambal elder Basil Djanghara said 'we got to make a big fire, big smoke on it so it's right for everyone to go there - we got to make a big smoke, sing out for him, we coming out for you, don't make trouble for us'.

As also described earlier, fire is used to 'clean up country' that may have become overgrown or unhealthy, especially if it has not been visited or burned in some years. Burning makes it easier to walk through areas and also reduces the risk of being bitten by poisonous snakes, which are abundant on many islands (O'Connor 1989). Sylvester Mangolamara took part in the KIBS on Mary Island and commented that the island was overgrown from too many years without fire, and that it was difficult to walk through much of the dense vegetation: 'Nobody burned that place for a long long time and its really scrubby, need to burn it to clear that place to make kangaroos healthy, burn it bit by bit, if we make one big fire what will happen to the animals? We need to let them smell that fire and move into another area'. Similarly, when he suggested that Bigge Island also needed to be burned in sections as spinifex had become overgrown and an uncontrolled wildfire could damage bush tucker tree species: 'Hot burn might buggerem up pinjeli [Ficus sp.], guleyi [Buchanania obovata], yowuru [Vitex acuminata], even waterfig [Ficus sp.]'. Matthew Waina considerd that Sir Graham Moore Island needed to be burnt because the vegetation had become too dense and overgrown, making it difficult to walk through. He was also concerned that the waterhole on the island had dried up and thought fire was needed to restore it. Clayton-Green and Beard (1985) also noted that vegetation on islands in the Admiralty Gulf had changed since the 1950s when Aboriginal people ceased regular visits and burning. They noted the spread of vine thicket elements into savanna vegetation associations.

There are instances where islands have been deliberately left unburnt to protect a plant resource, for example near beaches, not only because smoke repels sea turtles, but also because an unmanaged fire can damage fruit trees. Daphne Wilfred and her late brother Monty Wilfred have been cautious about fire on Long Island because of rock wallabies and the bush fruits (particularly gorrol, Buchanania obovata), which take a long time to recover after intense fires. Wunambal Gaambera elders have managed food resources by protecting the yams (Dioscorea transversa) on Mary Island from fire (Sylvester Mangolamara, pers. comm.). 


\section{FUTURE MANAGEMENT OF ISLANDS BY TRADITIONAL OWNERS}

TO groups have all been undertaking planning, both within their own cultural frameworks as well as negotiating with government agencies for at least the last 30 years to ensure long term beneficial natural and cultural resource management and implementation plans (see Johnston and Tann 1991; WGAC 2010). Significant threats to country have been identified, including some that are distinct from those identified by the non-indigenous community. Management solutions also often involve solutions that are unique to Indigenous people. For example, in the North Kimberley Saltwater Country Plan, TOs identified IPAs and Aboriginal Ranger Programs as useful mechanisms for managing country. The Wunambal Gaambera Aboriginal Corporation completed the Wunambal Gaambera Healthy Country Plan using the participatory planning tool 'Conservation Action Planning' (WGAC 2010). This plan identifies 'cultural sites on islands' as one of the 10 major targets to manage. Dambimangari, Balanggarra and Bardi Jawi TOs are also currently undertaking Conservation Action Planning and will have finalised cultural and natural resource management plans by the end of 2012.

\section{THREATS TO AND MANAGEMENT OF INDIGENOUS NATURAL AND CULTURAL VALUES ON ISLANDS}

A range of threats, identified by TOs, are impacting, or have the potential to impact, islands and their natural and cultural values. There are some differences in the threats identified by TOs compared to those identified by the mainstream conservation movement or documented in State Government planning documents (Cawardine et al. 2011; Government of Western Australia 2011).

The Saltwater Country Project identified lack of engagement with TOs as a threat to Indigenous values. There is a mixed history of Indigenous participation in research in the region. Many biological surveys have taken place in the past without any, or any meaningful, involvement of TOs. Moreover, the findings of these surveys have underpinned the declaration of national parks and reserves, which have subsequently led to the extinguishment of native title rights in the process, or additionally have had a detrimental impact on cultural values and the interests of TOs. The declaration of North Kimberley conservation reserves in 2000 without consultation with native title groups is an example of a poor engagement process that had a negative impact on cultural values and native title rights and interests (Crawford 2001). Moreover, policy and legislative changes often happen without consultation with
TOs, who are then required to respond to new changes affecting their country.

Unmanaged access by the expedition cruise industry and by independent travellers impacts on the cultural values by disturbing ancestral spirits which causes concern and spiritual harm to TOs (Scherrer et al. 2008, 2011; Smith et al. 2009; North Kimberley Saltwater Country Steering Committee 2010; Scherrer and Doohan 2011). Well known rock art sites at Bigge Island and Jar Island have become major tourism icons without any consultation with TOs. As well as causing cultural harm and trespass against native title rights, high visitation rates often results in damage, including deliberate harm such as graffiti, interference with human remains and the theft of artefacts, as well as increasing quarantine risks to biodiversity. Currently, TOs receive little or no benefit from these tourism enterprises, and as such, would prefer these areas be left undisturbed.

There is potential for feral animals to become established on islands if there are no appropriate quarantine procedures in place. In particular Cane Toads, house geckos and feral cats could impact on island fauna populations. Weeds have become established on some islands including large infestations of various species around the abandoned township site on Koolan Island. Stinking passionfruit (Passiflora foetida) has become established on some islands. Kapok Bush, Calotropis procera has become established on Adolphus Island and Lacrosse Island in Cambridge Gulf and is spreading west along the coast. It has also been recorded on some islands in the Bonaparte Archipelago (Neil Waina, pers. comm.). Visits by Indonesian fishermen and related marine debris pose quarantine risks. Fishermen sometimes carry livestock, cats and other pest animals on board their boats. They may also unknowingly carry animal and plant diseases. Additionally, unmonitored visitors also present quarantine risks through the spread of weeds, disease and feral animals such as Cane Toad and cats.

Iron ore mining on Cockatoo and Koolan islands has brought about significant and lasting physical changes to large parts of these islands and has also impacted on Aboriginal cultural values. Another mine is also being developed on the adjacent Irvine Island. The native title process provides the right for native title groups to negotiate with mining companies. Such negotiations often result in social and economic benefits like employment and compensation that is invested in community development projects that support the establishment of governance structures for native title groups.

Fire has been largely unmanaged on many remote islands since the 1950 s by which time most 
TOs had moved off country. Wildfires are now infrequent but when they do occur they are often high in intensity.

\section{CULTURALLY APPROPRIATE MANAGEMENT ARRANGEMENTS}

Important management strategies identified for North Kimberley islands include community led Indigenous rangers, IPAs, cultural and conservation partnerships, visitor management including the introduction of a visitor pass, tourism enterprises and community living areas. Many native title groups are developing a matrix of management options underpinned by partnerships to assist with the incremental implementation of long term visions for management of country.

Kimberley Aboriginal people have identified the indigenous ranger model as a way to manage country as well as to create employment. Bardi-Jawi Rangers were the first full-time ranger group to become established in the region (re-establishing after an earlier attempt in the 1990s). They were soon followed by a number of other groups with funding from the Australian Government's Working on Country Program, including the Uunguu Ranger group. Rangers patrol and look after their country under guidance from cultural advisors and with support from their prescribed body corporate, Aboriginal corporation or native title working group.

Most native title groups in the KIBS project area are exploring the creation of IPAs as a means of gaining greater protection and recognition for country (through the National Reserve System) and securing funding for management. In 2011, the Wunambal Gaambera Aboriginal Corporation declared stage I of the Uunguu Indigenous Protected Area. Stage II will include offshore islands and further mainland areas and stage III will include seas and the intertidal zone. Bardi and Jawi, Dambimangari and Balanggarra native title groups are also close to declaring IPAs in 2013. Other partnership and stewardship opportunities are emerging with the Western Australian Government under the Kimberley Science and Conservation Strategy and with nongovernment organisations such as The Nature Conservancy, PEW Environment Group and Bush Heritage Australia. Once ratified, recent amendments to the CALM Act (1984) will enable more flexible joint management arrangements with TOs and allow State laws to be applied to indigenous held lands (Conservation Legislation Amendment Bill 2010, extract from Hansard 6 April 2011).

As indicated above, the high levels of uncontrolled access to islands by the expedition cruise industry and independent tourists in boats and yachts is a concern to TOs. The Wunambal Gaambera Aboriginal Corporation has also developed the Uunguu Visitor Pass. Other groups are likely to establish similar passes. In a number of areas TOs are seeking to establish tourism enterprises as a way of benefitting from tourist visitation as well as managing tourism impacts on their country.

Many TOs would like to return to their traditional country and establish outstations/ homelands. As elder Daphne Wilfred lamented: 'The islands should be looked after, but there is 'no boat [we are] only looking at them from long way from One Arm Point". In the 1980s and 1990s, the Commonwealth Government provided significant funding to support this movement back to country. However, in recent years this funding has largely ceased. As a result, TOs are now considering new ways of getting back to country like coupling outstations with an enterprise to support remote livelihoods. Emerging markets in carbon and payment for ecosystem services provide new opportunities for TOs to sustainably live on country. More than likely the future of Indigenous management of islands will involve a combination of payments for environmental services coupled with investment from government programs and partnerships with non-government organizations. Mining, aquaculture and tourism are other alternatives. As this KIBS project has shown, biological surveys also present an emerging opportunity for people to get back on country.

\section{CONCLUSIONS}

The KIBS project provides an important precedent for how strategic regional research can be undertaken in partnership with TOs. The benefits of this approach include a shared vision, employment and participation of TOs and knowledge exchange. It is important for researchers to recognise that TOs must be consulted regarding access to country, in order to respect their ownership and to take into account their cultural values and their customary rights to country. Islands are integral components of complex cultural landscapes and seascapes believed to be inhabited by ancestral beings and deceased ancestors. As such, they include many important sacred and other significant sites. Researchers, like other visitors, should be introduced to country in the 'right way' (i.e. according to law and culture) and accompanied by the appropriate TOs to ensure a safe passage through country. Jawi families, connected to Sunday Island, were apprehensive about the KIBS saying they preferred that the island be left alone and not disturbed; however, they were 
satisfied that their permission was sought for the survey and that Bardi-Jawi rangers were supporting the research. Bardi-Jawi ranger Terry McCarthy described his role on the survey saying: 'I was the guide, so they went to the right places'.

Traditional Owners have Native Title rights and interests that extend beyond those of other stakeholders. Many native title groups in the North Kimberley hold exclusive possession native title, which means they hold the primary land management interest and veto powers over access to country. As identified through the Saltwater Country Project, a lack of consultation and culturally appropriate engagement poses a significant threat to the cultural values of islands. To redress this, TOs are seeking determinations of native title, declaring IPAs, and increasing their own capacity to undertake management actions through initiatives like the Australian Government Working on Country ranger program.

It is important for research agencies to collaborate with TOs in the design and conduct of field work associated with on-ground surveys. Research agreements that protect Aboriginal cultural and intellectual property rights are an important mechanism for initiating such collaboration. It is especially important that the planning be undertaken well before the research is to begin, so that TOs can share in establishing the research concept and design. Admittedly, this can be difficult due to the timeframes and complexities associated with securing funding, but collaborative planning to set research agendas can ensure the success of a project. Moreover, western scientific research agendas should be balanced with Indigenous priorities such as getting people back to country, passing on traditional knowledge and maintaining cultural sites and country management practices.

Islands are an integral part of the traditional country of Indigenous people in the Kimberley. Through planning processes, TOs have articulated threatening processes, from an Indigenous perspective, and identified management solutions. There is increasing awareness in natural and cultural resource management and research that programs should focus on delivering social as well as biodiversity outcomes. This project achieved significant social outcomes for TOs, including the casual employment of 50 indigenous people and opportunities for them to visit country. In the case of some Aboriginal participants, it was their first time on country. Finally, interactions between scientists and TOs have led to a better appreciation of the difference between western and traditional knowledge systems and cultures. In summary, research agreements that protect traditional cultural knowledge and the intellectual property rights of TOs are fundamental to the future success of research surveys in the Kimberley region of Western Australia. When undertaken in partnership, such agreements can lead to long term mutual benefits for all parties.

\section{ACKNOWLEDGEMENTS}

The authors would like to acknowledge the support of DEC in their commitment to culturally appropriate engagement of TOs in the Kimberley Islands Biological Survey. This project provided the opportunity to showcase the mutual benefits that can be achieved when working in partnership. Most importantly the authors would like to acknowledge the continuous commitment of TOs in their cultural leadership and stewardship of Kimberley country: mainland, sea, waters and islands. Please note that some Aboriginal people named in this document are now deceased as indicated by the ' $t$ ' symbol next to their name. Care should be taken in the use of these names among Indigenous relatives and communities.

\section{REFERENCES}

Akerman, K. (1975). The double raft or kalwa of the west Kimberley. Mankind 10: 20-23.

Akerman, K. (1979). Honey in the life of the Aboriginals of the Kimberleys. Oceania XLIX: 169-178.

Akerman, K. (1985). People of the ocean: tide riders of the Dampierland Peninsula. West Australian Social Science Education Consortium of the Western Australian Institute of Technology: Perth.

Akerman, K., Skyring, F. and Yu, S. (2010). The Indigenous cultural heritage values associated with pearl shell and pearling for the West Kimberley coast. Unpublished report to the Kimberley Land Council for the National Heritage assessment of the west Kimberley.

Aklif, G. (compiler) (1999). Ardiyoolooon Bardi Ngaanka: One Arm Point Bardi dictionary. Kimberley Language Resource Centre: Halls Creek, Australia.

Australian Heritage Commission (AHC) (2011). West Kimberley Place Report. http://www.environment. gov.au/heritage/places/national/west-kimberley/ pubs/ahc-final-assessment-full.pdf. Accessed 12 January 2012.

Basedow, H. (1918). Narrative of an expedition of exploration in north-western Australia. Transactions of the Royal Geographic Society of Australasia, South Australian Branch, Vol. xviii., Session 1916-1917: Adelaide.

Basedow, H. (1925). The Australian Aboriginal, 158-160. F.W. Preece and Sons: Adelaide.

Baudin, N. (1974). The journal of Post Captain Nicolas Baudin, Commander-in-Chief of the Corvettes Geographe and Naturaliste; assigned by order of the government to a voyage of discovery. Libraries Board of South Australia: Adelaide.

Bowern, C. (2007). Eels, dolphins and echidnas: Nyulnyulan prehistory through reconstruction of flora and fauna. In: Nussbaum, A. and Peters, S. 
(eds), Verba Docenti. Beechstave Press: Massachusetts, U.S.A. http://www.academia.edu/963337/On_Eels_ Dolphins_and_Echidnas_Nyulnyulan_Prehistory_ through_the_Reconstruction_of_Flora_and_Fauna. Accessed 5 December 2012.

Bowern, C. (2008). History of research on Bardi and Jawi. In: McGregor, W. (ed), History of research on Australian languages. Pacific Linguistics: Canberra.

Bowman, D.M.J.S., Price, O., Whitehead, P.J. and Walsh, A. (2001). The 'wilderness effect' and the decline of Callitris intratropica on the Arnhem Land Plateau, northern Australia. Australian Journal of Botany 49: 665-672.

Blundell, V. (1975). Aboriginal adaptation in northwest Australia. PhD thesis, University of Wisconsin: Maddison, U.S.A.

Blundell, V. (2003). The art of country: aesthetics, place, and Aboriginal identity in north-west Australia. In: Trigger, D. and Griffiths, G. (eds), Disputed territories: land, culture and identity in settler societies. Hong Kong University Press: Aberdeen, Hong Kong.

Blundell, V. and Doohan, K. (2009). Foundations: Indigenous concepts of dreaming and country. Unpublished report to the Kimberley Land Council regarding the Indigenous heritage values of the Kimberley region of north-west Australia.

Blundell, V., Doohan, K. and Bornman, J. (2009). Wanjina rock art, Gwion Gwion rock art and the Wanjina Wunggurr cultural landscape. Unpublished report to the Kimberley Land Council regarding the Indigenous heritage values of the Kimberley region of northwestern Australia.

Blundell, V. and Woolagoodja, D. (2005). Keeping the Wanjinas fresh: Sam Woolagoodja and the enduring power of Lalai. Fremantle Arts Press: Fremantle.

Brennan, K.E.C., Twigg, P.J., Watson, A., Pennington, A., Sumner, J., Davis, R., Jackson, J., Brooks, B., Grant, F. and Underwood, R. (2012). Cross-cultural systematic biological surveys in Australia's Western Desert. Ecological Management and Restoration 13: 72-80.

Brock, J. (1997). Native plants of northern Australia. Reed Books: Kew, U.K.

Burbidge, A.A., McKenzie, N.L. and Kenneally, K.F. (1991). Nature conservation reserves in the Kimberley Western Australia. Department of Conservation and Land Management: Perth.

Burbidge, A.A. and McKenzie, N.L. (1978). The islands of the north-west Kimberley: Western Australia. Wildlife Research Bulletin Western Australia No. 7. Department of Fisheries and Wildlife: Perth.

CALM (1994). A representative marine reserve system for Western Australia. Department of Conservation and Land Management: Perth.

Capell, A. (1941). Notes on the Wunambal language. Oceania 11: 295-308.

Carwardine, J., O'Connor, T., Legge, S., Mackey, B., Possingham, H. and Martin, T. (2011). Priority threat management to protect Kimberley wildlife. CSIRO Ecosystem Sciences: Brisbane.

Chalarimeri, A.M. (2001). The man from the sunrise side. Magabala Books: Broome, Australia.

Choo, C. (2001). Mission girls: Aboriginal women on Catholic missions in the Kimberley, Western Australia, 1900-1950. University of Western Australia Press: Crawley.

Clayton-Greene, K.A. and Beard, J.S. (1985). The fire factor in vine thicket and woodland vegetation of the Admiralty Gulf region, north-west Kimberley, Western Australia. Proceedings of the Ecological Society of Australia 13: 225-230.

Clendon, M. (compiler) (2000). A provisional Worrorra dictionary. Kimberley Language Resource Centre: Halls Creek, Australia.

Crawford, I.M. (1968). The art of the Wandjina: aboriginal cave paintings in Kimberley, Western Australia. Oxford University Press: Melbourne.

Crawford, I.M. (1969). Late prehistoric changes in Aboriginal cultures in Kimberley, Western Australia. PhD thesis, University of London.

Crawford, I.M. (1982). Traditional Aboriginal plant resources in the Kalumburu area: aspects in ethnoeconomics. Records of the Western Australian Museum, Supplement 15: 1-86.

Crawford, I.M. (1983). Aboriginal exploitation of resources, Admiralty Gulf. In: Smith, M. (ed), Archaeology at ANZAAS, 45-51. Western Australian Museum: Perth.

Crawford, I.M. (2001). We won the victory: Aborigines and outsiders on the north-west coast of the Kimberley. Fremantle Arts Centre Press: Fremantle.

Crawford, I.M. (2009). 'Macassan' voyaging to Kimberley and its impact on Aboriginal heritage. Unpublished report to the Kimberley Land Council for the National Heritage assessment of the west Kimberley.

Dampier, W. (1981). A voyage to New Holland: the English voyage of discovery to the South Seas in 1699. Alan Sutton: Gloucester, U.K.

Edwards, H. (1991). Kimberley: dreaming to diamonds. Selfpublished.

Fitzsimons, J., Russell-Smith, J., James, G., Vigilante, T., Lipsett-Moore, G., Morrison, J. and Looker, M. (2012). Insights into the biodiversity and social benchmarking components of the northern Australian fire management and carbon abatement programmes. Ecological Management and Restoration 13: 51-57.

Gibson, L.A. and McKenzie, N.L. (2012). Identification of biodiversity assets of selected Kimberley islands: background and implementation. Records of the Western Australian Museum, Supplement 81: 1-14.

Government of Western Australia (2011). Kimberley science and conservation strategy. Government of Western Australia: Perth. http://www.dec.wa.gov. au/content/view/6558/2378/

Green, N. (1988). The Oombulgurri story: a pictorial history of the people of Oombulgurri, 1884-1988. Focus Education Services: Cottesloe, Australia.

Green, N. (2008). The Forrest River massacres. Focus Education Services: Cottesloe, Australia.

Hassell, C. and Boyle, A. (2002). Breeding Roseate Terns in the Kimberley. WA Bird Notes 101: 12-13.

Hernandez, T. (1941). Social organisation of the Drysdale River tribes. Oceania 11: 211-232

Horstman, M. and Wightman, G. (2001). Karparti ecology: recognition of Aboriginal ecological knowledge and its application to management in north-western 
Australia. Ecological Management and Restoration 2: 99-109.

Hynes, R.A. and Chase, A.K. (1982). Plants, sites and domiculture: Aboriginal influences upon plant communities in Cape York Peninsula. Archaeology in Oceania 17: 38-50.

Jebb, M.A. (2002). Blood, sweat and welfare: a history of white bosses and Aboriginal pastoral workers. University of Western Australia Press: Nedlands.

Johnston, R. and Tann, T. (1991). Interim report of the National Parks and Conservation Research and Policy Unit 1990. Aboriginal Affairs Planning Authority: Perth.

Kaberry, P.M. (1934). Forrest River Genealogies. Unpublished field notes. Australian Institute of Aboriginal and Torres Strait Islander Studies, MS 739/2, Items 1, 2 and 13.

Kaberry, P.M. (1935a). The Forrest River and Lyne River Tribes of north-west Australia: a report on field work. Oceania 5: 408-436.

Kaberry, P.M. (1935b). Death and deferred mourning ceremonies in the Forrest River tribes, north-west Australia. Oceania 5: 33-47.

Karadada, J., Karadada, L., Goonack, W., Mangolamara, G., Bunjuck, W., Karadada, L., Djanghara, B., Mangolamara, S., Oobagooma, J., Charles, A., Williams, D., Karadada, R., Saunders, T. and Wightman, G. (2011). Uunguu plants and animals: Aboriginal biological knowledge from Wunambal Gaambera Country in the north-west Kimberley, Australia. NTBB 35. Department of Natural Resources, Environment, the Arts and Sport: Darwin, Australia.

Kenneally, K.F., Edinger, D.C. and Willing, T. (1996). Broome and beyond: plants and people of the Dampier Peninsula, Kimberley, Western Australia. Conservation and Land Management: Perth.

Kennett, R. and Kitchens, J. (2009). Dugong and marine turtle project. Final report to National Heritage Trust Regional Competitive Component. http://www. nailsma.org.au/hub/resources/publication/nailsmadugong-and-marine-turtle-project-final-report-2009. Accessed 28 November 2012.

Kimberley Land Council (KLC) (2000). North Kimberley Traditional Owners Land and Sea Management Project: Final Report, Wunambal Gaambera and Balanggarra Traditional Owners, Glenn Wightman, Sylvester Mangolamara and Darryl Smith, March 2000.

Kimberley Land Council (KLC) (2010). Kimberley LNG precinct strategic assessment. Indigenous Impacts Report Volume 4: Report on Heritage Impact Assessment. http://www.dsd.wa.gov.au/ documents/Appendix_E-4.pdf. Accessed 10 February 2012.

King, P.P. (1969). Narrative of a survey of the intertropical and western coasts of Australia performed between the years 1818 and 1822 (Two volumes). Libraries Board of South Australia: Adelaide.

Lands, M. (1997). Mayi: some bush fruits of the West Kimberley. Magabala Books: Broome, Australia.

Lommel, A. (1997). [1952]. The Unambal: a tribe in northwest Australia. Ian Campbell, trans. Carnavon Gorge via Rolleston. Queensland. Takarakka Nowan
Kas Publications. [Orig. Die Unambal: Ein Stamn in nordwest Australien, Monographien zur Volkerkunde herausgegben vom Hamburgischen Museum fuer Volkerkunde].

Love, J.R.B. (1936). Stone Age bushmen of today. Blackie and Sons Ltd: London and Glascow.

Love, J.R.B. (1938). Illustrations of stone monuments of the Worora. Records of the South Australia Museum 6: 137-142.

Mangglamara, G., Burbidge, A.A. and Fuller, P.J. (1991). Wunambal words for rainforest and other Kimberley plants and animals (pp. 413-421). In: McKenzie, N.L., Johnston R.B. and Kendrick P.K. (eds), Kimberley rainforests of Australia. Surrey Beatty and Sons: Chipping Norton, Australia.

Martin, J. (1864). Report for the information of H. E. the Governor of Western Australia and the promotors of the North-West expedition of 1864 on the voyage and the resources of the districts explored. In: Martin, J., Journals and reports of two voyages to the Glenelg River and the north-west coast of Australia, 1863-4. Perth.

McGonigal, D. (1998). The Australian Geographic book of the Kimberley. The Australian Geographic: Terry Hills, Australia.

McGregor, W. (2004). The languages of the Kimberley, Western Australia. Routledge Curzon: Oxfordshire, U.K.

McGregor, W. and Rumsey, A. (2009). Worrorran revisited - the case for genetic relations among languages of the northern Kimberley region of Western Australia. Pacific Linguistics: Canberra.

McKenzie, N.L., Johnston, R.B. and Kendrick, P.K. (1991) Kimberley rainforests of Australia. Surrey Beatty and Sons: Chipping Norton, Australia.

McNiven, I.J. and Russell, L. (2005). Appropriated pasts: indigenous peoples and the colonial culture of archaeology. Altamira Press: Lanham, U.S.A.

Moorcroft, H., Ignjic, E., Cowell, S., Goonack, J., Mangolomara, S., Oobagooma, J., Karadada, R., Williams, D. and Waina, N. (2012). Conservation planning in a cross-cultural context: the Wunambal Gaambera Healthy Country Project in the Kimberley, Western Australia. Ecological Management and Restoration 13: 16-25.

Mowaljarlai, D. and Malnic, J. (2001). Yorro Yorro, everything standing up alive. Magabala Books: Broome, Australia.

Mulvaney, D. J. and Kamminga, J. (1999). Prehistory of Australia. Smithsonian Institute Press: Washington D.C.

Ngarjno, Ungudman, Banggal and Nyawarra (2000). Gwion Gwion: secret and sacred pathways of the Ngarinyin Aboriginal people of Australia. Doring, J. (ed). Konemann: Cologne, Germany.

North Kimberley Saltwater Country Plan for Balanggarra, Uunguu, Dambimangari and Mayala Saltwater Country (2010). Unpublished report prepared by the North Kimberley Saltwater Steering Committee with the assistance from the Kimberley Land Council.

O'Connor, S. (1989). Contemporary island use in the west Kimberley, Western Australia, and its implications 
for archaeological site survival. Australian Aboriginal Studies 2: 25-31.

O'Connor, S. (1987). The stone house structures of High Cliffy Island, northwest Kimberley, Western Australia. Australian Archaeology 25: 30-39.

Paddy, E. and Smith, M. (1987). Boonja Bardag Gorna: all trees are good for something. Community Report 87/1, Anthropology Department, Western Australian Museum: Perth.

Pearson, D.J. and the Ngaanyatjarra Council (1997). Aboriginal involvement in the survey and management of rock-wallabies. Australian Mammalogy 19: 249-256.

Perez, E. (1977). Kalumburu: the Benedictine Mission and the Aborigines, 1908-1975. Kalumburu Benedictine Mission: Kalumburu, Australia.

Perez, E. (1986). The diary of Bishop Torres. Artlook Books: Perth.

Petri, H. (1938/40). Mythische heroen und urzeitlegende in Nordlichen Dampierland, Nordwest-Australien, Paiduema 1: 217-230. ("Mythical heroes and Dreamtime legends in northern Dampierland, northwest Australia"). German translation by Christiane Fennell for the Kimberley Land Council.

Richards, C. (1990). There were three ships: the story of the Camden Harbour Expedition, 1864-5. University of Western Australia Press: Nedlands.

Rouja, P.M. (1998). Fishing for culture: toward an Aboriginal theory of marine resource use among the Bardi Aborigines of One Arm Point. PhD Thesis, University of Durham: Durham, U.K.

Sholl, T. (1865). Journal typescript. Battye Library: Perth.

Scherrer, P. and Doohan, K. (2011). Capturing intangible cultural impacts of tourism on Aboriginal land in Australia's Kimberley Region. Tourism Recreation Research 36: 271-280.

Scherrer, P., Smith, A.J. and Dowling, R. (2008). Tourism and the Kimberley coastal waterways: a review of environmental and cultural aspects of expedition cruising along the Kimberley coast, Western Australia. Unpublished report, Sustainable Tourism Cooperative Research Centre: Queensland.

Scherrer, P., Smith, A.J. and Dowling, R. (2011). Environmental and cultural implications of visitor access in the Kimberley region, Australia. Australian Geographer 42: 257-271.

Smith, A.J., Scherrer, P. and Dowling, R. (2009). Impacts on Aboriginal spirituality and culture from tourism in the coastal waterways of the Kimberley region, north west Australia. Journal of Ecotourism 8: 82-98.

Smith, M. (1997). Fish-capture sites and the maritime economies of some Kimberley coastal Aboriginal communities. Anthropology Department, Western Australian Museum. Western Australian Government: Perth.

Smith, M. and Kalotas, A.C. (1985). Bardi plants: an annotated list of plants and their use by the Bardi
Aborigines of Dampierland, in north-western Australia. Records of the Western Australian Museum 12: 317-359

Stanner, W.E.H. (1979). White man got no dreaming; Essays 1938-1973. Australian National University Press: Canberra.

Stanner, W.E.H. (1987). The Dreaming (pp 225-235). In: Edwards W.H. (ed), Traditional Aboriginal society: a reader. McMillan: Crows Nest, Australia.

Stokes, J.L. (1846). Discoveries in Australia: with an account of the coasts and rivers explored and surveyed during the voyage of H.M.S. Beagle in the years 1837-38-39-40-41-42-43. (Two volumes). T. and W. Boone: London, 1969 edition. Libraries Board of South Australia: Adelaide.

Stuart, E.J. (1923). A land of opportunities: being an account of the author's recent expedition to explore the Northern Territories of Australia. John Lane the Bodley Head Ltd: London.

The Nature Conservancy (2011). Conservation Action Planning. http://www.conservationgateway.org/ topic/conservation-action-planning.html. Accessed 21 September 2011.

Tindale, N.B. (1940). Distribution of Australian Aboriginal tribes: a field survey. Transactions of the Royal Society of South Australia, Adelaide 64: 140-231.

Tindale, N.B. (1974). Aboriginal tribes of Australia: their terrain, environmental controls, distribution, limits, and proper names. Australian National University Press: Canberra.

Vachon, D. (2009). Double log raft. Unpublished report to the Kimberley Land Council for the National Heritage List assessment of the west Kimberley.

Vigilante, T. (2001). Analysis of explorers' records of Aboriginal landscape burning in the Kimberley region of Western Australia. Australian Geographical Studies 39: 135-155.

Vigilante, T., Bowman, D.M.J.S., Fisher, R., Russell-Smith, J. and Yates, C. (2004). Contemporary landscape burning patterns in the far north Kimberley region of north-west Australia: human influences and environmental determinants. Journal of Biogeography 31: 1317-1333.

Vigilante, T. (2004). The ethnoecology of landscape burning around Kalumburu, North Kimberley. PhD Thesis, Northern Territory University: Darwin, Australia.

Wheeler, J.R. (ed) (1992). Flora of the Kimberley region. Department of Conservation and Land Management: Perth.

Wunambal Gaambera Aboriginal Corporation (WGAC) (2010). Wunambal Gaambera Healthy Country Plan - Looking after Wunambal Gaambera Country 2010-2020.

MANUSCRIPT RECEIVED JULY 2012; ACCEPTED DECEMBER 2012. 
APPENDIX 1 Traditional Owner participation in the surveys. Altogether, some 50 TOs from five Native Title claim groups participated in the field component of the survey over a 4-year period (Note ${ }^{\dagger}$ indicates person is now deceased).

\begin{tabular}{|c|c|c|c|}
\hline Survey & Islands & Traditional Owners & Claim \\
\hline \multirow[t]{9}{*}{ Dry season 2007} & Bigge & Sylvia Djanghara & Uunguu \\
\hline & Boongaree & Dorothy Djanghara & \\
\hline & & Warren Djanghara & \\
\hline & Katers & Jeremy Kowan & \\
\hline & Middle Osborn & Neil Waina & \\
\hline & & Derek Charles & \\
\hline & South West Osborn & Damien Lawford & \\
\hline & Sir Graham Moore & Charlie Bundamurra & Balanggarra \\
\hline & & Damien Lawford & \\
\hline Wet season 2008 & $\begin{array}{l}\text { Various islands in the } \\
\text { Uunguu native title area plus } \\
\text { Sir Graham Moore in the } \\
\text { Balanggarra area }\end{array}$ & $\begin{array}{l}\text { Jason Adams } \\
\text { Alphonse Fredericks } \\
\text { Jeremy Kowan } \\
\text { Shane Undalgamen }\end{array}$ & $\begin{array}{l}\text { Uunguu } \\
\text { (+ Balanggarra for SGM) }\end{array}$ \\
\hline April 2008 recon. flight & Various islands & Peter Pedersen & Dambimangari \\
\hline \multirow[t]{20}{*}{ Dry season 2008} & Coronation 1 & John Jangoot & Uunguu \\
\hline & & Maitland Ngerdu & \\
\hline & Coronation 2 & Craig Rastus & \\
\hline & & Pedro Palacios & \\
\hline & St Andrew & Sonnette Ozies & \\
\hline & & Jeanine Numendumah & Dambimangari \\
\hline & Augustus 1 & Edmund Lee Ngerdu Jnr & Dambimangari \\
\hline & & Thorvald Ozies & \\
\hline & Augustus 2 & Elvina Oobagooma & \\
\hline & & Deidre Mungulu & \\
\hline & Uwins & Victor Barunga $^{\dagger}$ & \\
\hline & & Wayne Oobagooma & \\
\hline & Byam Martin & Alfred Umbagai & \\
\hline & & Duane Ngerdu & \\
\hline & Jungulu/Darcy 1 & Kirk Woolagoodja & \\
\hline & & Brett Oobagooma $^{+}$ & \\
\hline & Jungulu/Darcy 2 & Anita Umbagai & \\
\hline & & Jacqueline Mungulu & \\
\hline & Adolphus & Lionel Mitchell & Balanggarra \\
\hline & & Kevin Morgan & \\
\hline
\end{tabular}




\begin{tabular}{|c|c|c|c|}
\hline Survey & Islands & Traditional Owners & Claim \\
\hline \multirow[t]{2}{*}{ Wet season 2009} & $\begin{array}{l}\text { Islands in the Dambimangari } \\
\text { and Uunguu native title areas }\end{array}$ & $\begin{array}{l}\text { Alfred Umbagai } \\
\text { Tristan Burgu }\end{array}$ & Dambimangari / Uunguu \\
\hline & Adolphus & Lionel Mitchell & Balanggarra \\
\hline 2008 recon. flight & & $\begin{array}{l}\text { Aubrey Tigan } \\
\text { Sandy Isaac }\end{array}$ & $\begin{array}{l}\text { Mayala } \\
\text { Bardi and Jawi }\end{array}$ \\
\hline \multirow[t]{9}{*}{ Dry season 2009} & NW Molema (Talbot Bay) & $\begin{array}{l}\text { Thorvald Ozies } \\
\text { Sonnette Ozies }\end{array}$ & Dambimangari \\
\hline & Wulalam & $\begin{array}{l}\text { Alfred Umbagai } \\
\text { Anita Umbagai }\end{array}$ & \\
\hline & Kingfisher & $\begin{array}{l}\text { Wayne Oobagooma } \\
\text { Pedro Palacios }\end{array}$ & \\
\hline & Storr & $\begin{array}{l}\text { Jordan Barunga } \\
\text { Craig Rastus }\end{array}$ & \\
\hline & Un-named (near Storr) & $\begin{array}{l}\text { John Jangoot } \\
\text { Edmund Lee Ngerdu Jnr }\end{array}$ & \\
\hline & Hidden & $\begin{array}{l}\text { Mitchell Tigan } \\
\text { Aubrey Tigan } \\
\text { Jahni Isaac }\end{array}$ & Mayala \\
\hline & Long & $\begin{array}{l}\text { Sandy Isaac } \\
\text { Jahni Isaac } \\
\text { Kalvin Hudson }\end{array}$ & \\
\hline & Lachlan & Aaron Mungulu & \\
\hline & Sunday & $\begin{array}{l}\text { Nathan Sampi (BJ Ranger) } \\
\text { Terry McCarthy (BJ Ranger) } \\
\text { Herman Ishmail - } \\
\text { Traditional Owner }\end{array}$ & Bardi and Jawi \\
\hline \multirow[t]{3}{*}{ Wet season 2010} & $\begin{array}{l}\text { NW Molema } \\
\text { Wulalam } \\
\text { Kingfisher } \\
\text { Storr } \\
\text { Un-named (near Storr) }\end{array}$ & $\begin{array}{l}\text { Craig Rastus } \\
\text { Ian Heally }\end{array}$ & Dambimangari \\
\hline & $\begin{array}{l}\text { Hidden } \\
\text { Lachlan } \\
\text { Long }\end{array}$ & $\begin{array}{l}\text { Lionel Cox } \\
\text { Craig Isaac }\end{array}$ & Mayala \\
\hline & Sunday & $\begin{array}{l}\text { Trevor Sampi (BJ Ranger) } \\
\text { Terry McCarthy (BJ Ranger) } \\
\text { Herman Ishmail - } \\
\text { Traditional Owner }\end{array}$ & Bardi and Jawi \\
\hline Dry season 2010 & $\begin{array}{l}\text { Mary } \\
\text { Wargul Wargul }\end{array}$ & $\begin{array}{l}\text { Sylvester Mangolamara } \\
\text { Desmond Williams } \\
\text { Bruce Oxtoby }\end{array}$ & Uunguu \\
\hline
\end{tabular}


